\title{
Conservación del arte contemporáneo
}

\section{El caso de Mathias Goeritz en la Catedral Metropolitana de México}

\author{
Conservation of contemporary art: The case of Mathias Goeritz in the Metropolitan Cathedral of \\ Mexico \\ Conservação da arte contemporânea: o caso de Mathias Goeritz na Catedral Metropolitana do México
}

\section{Alberto Cedeño-Valdiviezo Pablo Torres-Lima}

Universidad Autónoma Metropolitana, Xochimilco, Ciudad de México (México)

División de Ciencias y Artes para el Diseño

División de Ciencias Biológicas y de la Salud

Cedeño-Valdiviezo, A., \& Torres-Lima, P. (2019). Conservación del arte contemporáneo: el caso de Mathias Goeritz en la Catedral Metropolitana de México. Revista de Arquitectura (Bogotá), 2/(I), 44-53. doi: http://dx.doi.org//0.147/8/ RevArq.2019.21.1.2304

\author{
Alberto Cedeño-Valdiviezo \\ Doctor en Urbanismo, Universidad Nacional Autónoma de México \\ (UNAM), México. \\ Posdoctorado en Habitabilidad y Protección del Medioambiente, \\ Universidad de Buenos Aires (UBA), Argentina. \\ Miembro del Sistema Nacional de Investigadores, nivel I, del Con- \\ sejo Nacional de Ciencia y Tecnología (Conacyt) \\ (D) http://orcid.org/0000-0002-I464-0I00 \\ alberto_cede@yahoo.com.mx \\ Pablo Torres-Lima \\ Doctor en Antropología, University of Florida, EE.UU. \\ Miembro del Sistema Nacional de Investigadores, nivel II, del Con- \\ sejo Nacional de Ciencia y Tecnología (Conacyt) \\ (1D) https://orcid.org/0000-000I-5253-8580 \\ ptorres@correo.xoc.uam.mx
}

\section{Resumen}

La obra del artista polaco alemán Mathias Goeritz -y los vitrales insertos en la Catedral Metropolitana de la Ciudad de México, que a la fecha están en riesgo de ser retirados- es cuestionada desde su creación por el lenguaje moderno que contrasta con el estilo arquitectónico del edificio religioso. Esto pone en discusión el conflicto que se origina entre obras modernas, artistas extranjeros y edificaciones de carácter patrimonial. El estudio se realizó a partir de una revisión documental que recurrió principalmente a literatura italiana y mexicana para, por medio de la definición conceptual de obra de arte, reconocer el valor de estos vitrales. El desarrollo plantea dos argumentos, el primero reconoce un rechazo debido a que el lenguaje utilizado por estos artistas no corresponde al lenguaje de la arquitectura de los inmuebles patrimoniales, a pesar de que esta práctica es habitual en algunos países europeos; $y$, el segundo, asume un rechazo como consecuencia de los valores inculcados por el Estado después de la Revolución mexicana, que fomentan lo nacional y rechazan lo extranjero. Esto sirvió para evaluar los posibles argumentos y las formas legales para la protección de los vitrales contemporáneos.

Palabras clave: arquitectura mexicana; arquitectura religiosa; arte mexicano; monumentos; patrimonio material; vitrales.

\section{Abstract}

The work of Polish-German artist Mathias Goeritz-more specifically, his stained-glass windows in the Metropolitan Cathedral of Mexico City that, currently, are at risk of being removed-has been questioned since its creation in 1960, given that its modern language is in contrast with the architectural style of the religious building. This situation opens the discussion of a problem that arises when modern art works carried out by foreign artists are placed in religious buildings of patrimonial character. It is difficult to understand whether this discussion is, in effect, a rejection of the artistic language used by modern artists, since it does not correspond to the architectural language of historical buildings, despite the fact that this practice is common in some European countries, or whether this rejection is rather a consequence of the values inculcated by the Mexican State after the Mexican Revolution, which promote the National Spirit and reject everything foreign. This paper aims to determine which of these arguments is relevant in the case of Goeritz's work. Through the conceptual definition of work of art, it seeks to identify the real value of these stained glass windows, and which are the most effective legal forms to protect them.

Keywords: Mexican architecture; religious architecture; Mexican art; monuments; material heritage; stained glass windows.

\section{Resumo}

A obra do artista polaco-alemão Mathias Goeritz — e os vitrais da Catedral Metropolitana da Cidade do México, que, neste momento, estão em risco de serem retirados - é questionada por causa da linguagem moderna que contrasta com o estilo arquitetônico do edifício religioso. Isso coloca em debate o conflito que é originado entre obras modernas, artistas estrangeiros e edificações de caráter patrimonial. Este estudo foi realizado com base numa revisão documental que recorreu principalmente à literatura italiana e mexicana para, por meio da definição conceitual de obra de arte, reconhecer o valor desses vitrais. O desenvolvimento propõe dois argumentos: o primeiro reconhece uma rejeição devido à linguagem utilizada por esses artistas não corresponder à linguagem da arquitetura dos imóveis patrimoniais, embora essa prática seja habitual em alguns países europeus; o segundo assume uma rejeição como consequência dos valores estabelecidos pelo Estado depois da Revolução mexicana, que fomentam o nacional e rejeitam o estrangeiro. Isso serviu para avaliar os possíveis argumentos e as formas legais para proteger os vitrais contemporâneos.

Palavras-chave: arquitetura mexicana; arquitetura religiosa; arte mexicana; monumentos; patrimônio material; vitrais. 


\section{Introducción}

Esta investigación, financiada por la Universidad Autónoma Metropolitana, de Xochimilco, tiene su origen en el posgrado de la División de Ciencias y Artes para el Diseño, cuyo objetivo era conocer la situación de los vitrales contemporáneos en edificios antiguos en México, buscando identificar los elementos que hicieran posible una efectiva protección. Este artículo se puede considerar como una continuación de la publicación El gótico y los vitrales (2014), de Alberto Cedeño-Valdiviezo y Claudia Huidobro-Olvera, en el cual se abordó el tema del origen de los vitrales y su posterior evolución.

El objetivo principal de este nuevo artículo es analizar las razones de la problemática que se presenta, frente a la conservación de aquellos vitrales elaborados por artistas contemporáneos realizados en iglesias con alto valor patrimonial, considerando la existencia de marcos legales para su protección.

La razón de abordar esta problemática se debe al afán de algunos restauradores mexicanos prestigiosos por destruir los mencionados vitrales, con el argumento de que el lenguaje artístico utilizado por los artistas contemporáneos contrasta, de manera inadecuada, con el estilo arquitectónico del edificio religioso, por tanto, proponen que las obras sean removidas y sustituidas. Particularmente, se analizarán los vitrales propuestos y ejecutados por el artista contemporáneo de origen polaco alemán Mathias Goeritz, en la Catedral Metropolitana de la Ciudad de México (Figura 1)

En opinión de algunos autores, en México se tiene una manera muy particular de referirse al patrimonio; en primer lugar, lo prehispánico parece tener un mayor valor que lo colonial, que a su vez se reconoce como superior al arte contemporáneo (Escalante, 2011). Particularmente, en la memoria de los mexicanos, pero también en su vida cotidiana, las iglesias y los templos están rodeados de sentimientos intensos y emociones muchas veces contradictorias. Por un lado, estos generan júbilo y orgullo por un pasado rico y majestuoso, pero, por el otro, producen resentimiento y odio hacia los españoles que ordenaron su construcción y que en el alma de los mexicanos siguen siendo los enemigos y opresores. El liberalismo anticlerical del siglo XIX, y el nacionalismo revolucionario del siglo $X X$ se encargaron de privilegiar el patrimonio arqueológico, aunque en las últimas décadas el discurso de la historia oficial se ha transformado (Roselló, 2011).

Las iglesias son lugares de diálogo y encuentro, esenciales en la vida cotidiana comunitaria e individual, y constituyen un acervo invaluable que nutre la memoria colectiva de esta nación. Las grandes catedrales e iglesias barrocas acercan a los mexicanos a un pasado majestuoso, rico, monumental, que le da a este país grandeza y suntuosidad. Pero más allá de las creencias religiosas, ya en el siglo XXI las iglesias, capillas y catedrales de la época virreinal son edificaciones que funcionan como importantes centros de socialización, reunión, diálogo y encuentro: vinculan lo terrenal con lo celestial; la historia con la cotidianidad; y el patrimonio arquitectónico y artístico con costumbres, hábitos y formas de vivir que identifican a los mexicanos (Roselló, 2011).

Sin embargo, desde el principio del siglo pasado, el nacionalismo posrevolucionario, en la búsqueda de crear "identidades culturales", terminó por manipular y negar la pluralidad y versatilidad de las culturas locales, las cuales se señalaban como identidades falsas, de pacotilla o de oropel, y que hoy en día, infortunadamente, se repiten y se afirman como imágenes que identifican a amplios sectores nacionales frente a sí y ante los ojos de los visitantes extranjeros (Pérez, 2011). Ante este marco de cultura nacionalista, que encuadra aún la comprensión y valoración del patrimonio arquitectónico mexicano en la actualidad, surge una pregunta importante: ¿cómo es posible evaluar correctamente la obra de un artista extranjero en México?, que, además, se atrevió a plasmar su obra en la iglesia o catedral colonial de mayor importancia nacional. Los objetivos de este artículo son la posible protección de estas obras de arte y entender la manera como los mexicanos evaluamos este patrimonio.

Es importante aclarar que, así como sucede en otros países, la Iglesia católica en México siempre ha necesitado del trabajo del artista creativo, que se encuentra un paso adelante, para expresarle al creyente, mediante sus obras, que existe una continuidad entre la Iglesia antigua y la

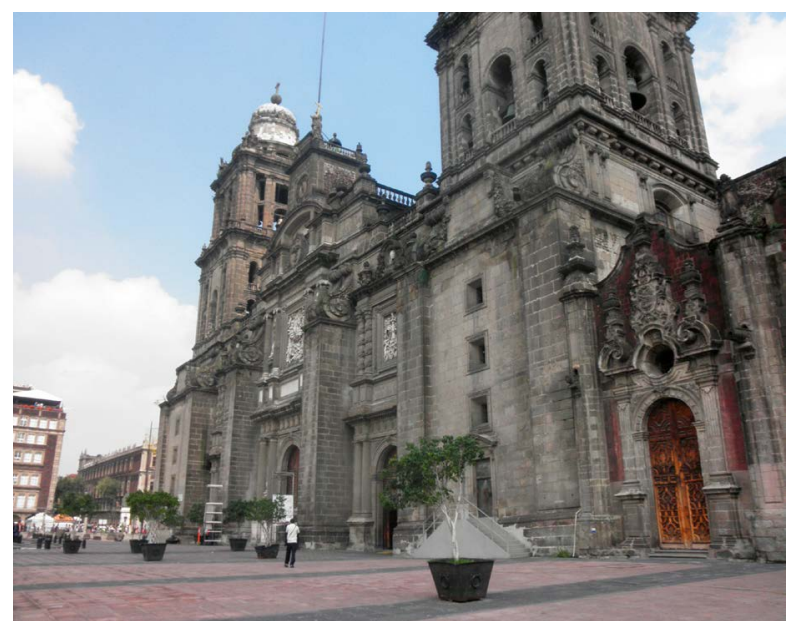

igura 1. Catedral Metropolitana de la Ciudad de México

Fuente: Cedeño, 2015

This article is available in English on the website of Revista de Arquitectura (Bogotá) doi: http://dx.doi.org/10.14718/RevArq.2019.21.1.2304

Conservation of contemporary art: The case of Mathias Goeritz in the Metropolitan Cathedral of Mexico. 


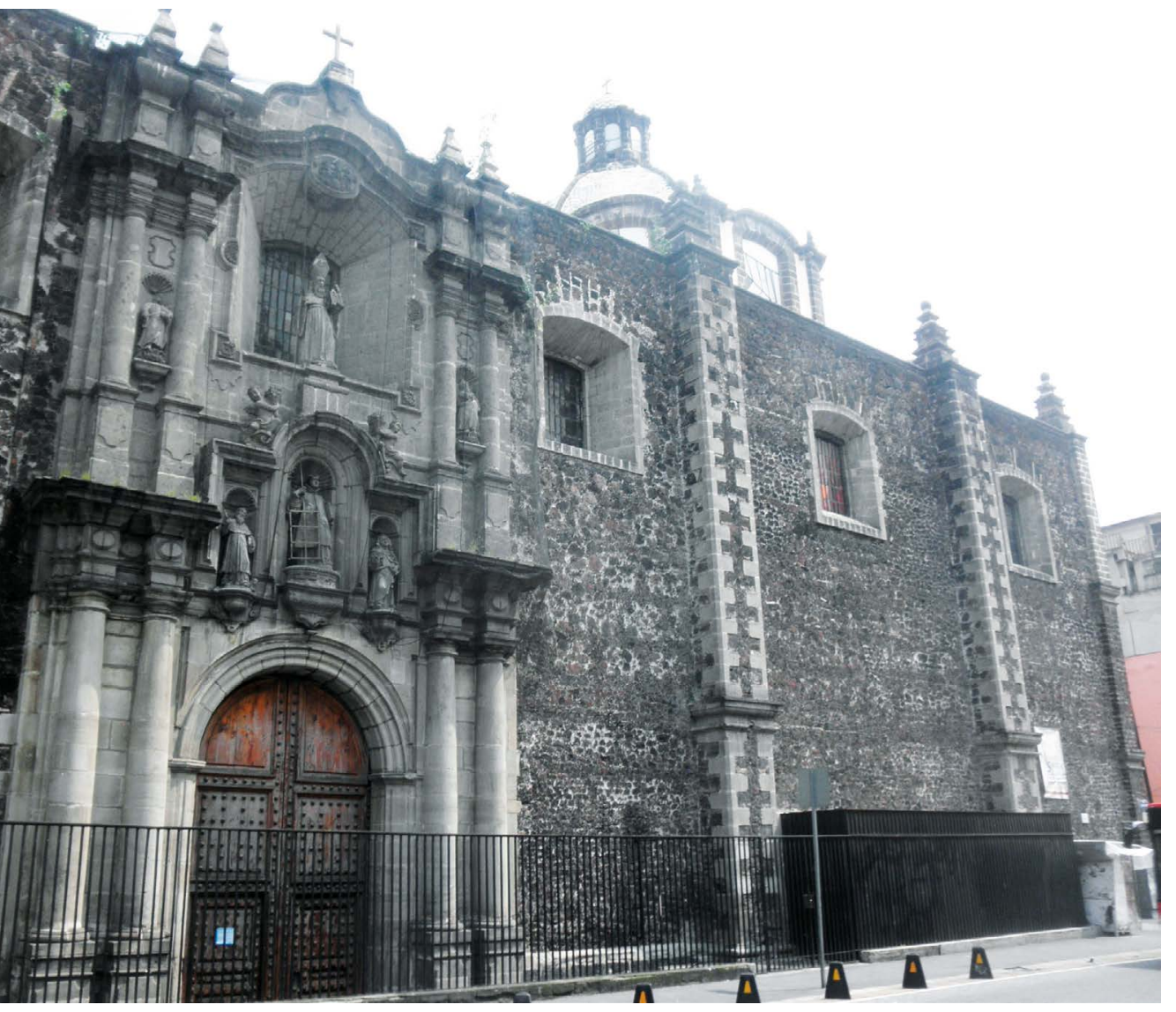

(A) Figura 2. Parroquia de San Lorenzo Mártir, donde trabajó Mathías antes de hacerse cargo de los vitrales de la Catedral

Fuente: Cedeño, 2018. de hoy, por medio de la expresión artística de nuestro tiempo. Por medio de la obra artística contemporánea, el creyente puede sentir lo que significa creer y relacionarse con la divinidad o las deidades, y, así, construir su experiencia religiosa; pero no solo el creyente, también el viajero tiene la posibilidad de acceder al disfrute del espacio y la experiencia estética del arte religioso (Huidobro, 2014).

\section{Metodología}

En este trabajo se revisaron los diversos aportes conceptuales sobre lo que se debe entender por obra de arte según los insignes maestros italianos Carlo Ceschi, en su Teoria e restauro dei monumenti (1970), y Césare Brandi en su Teoria del restauro (1977), además de otros autores, buscando entender por qué un objeto puede ser reconocido como tal, y cuáles serían los procedimientos para que estas obras de arte pudieran recibir una efectiva protección. Para tal fin, se construyó un modelo explicativo de la condición e historicidad de estos vitrales, y las verdaderas causas que buscan su desaparición. Posteriormente, se revisaron los principales criterios de la legislación mexicana sobre el patrimonio artístico, para esclarecer aquellos mecanismos legales que pudieran ser utilizados en la búsqueda de su efectiva protección.

El principal enfoque consistió en la delimitación del tema de investigación, para lo cual se presenta el caso de los vitrales de Mathías Goeritz; posteriormente, se asumió la tarea de investigar la relación histórica de los mexicanos con su patrimonio, y cómo estos reciben y perciben la obra de los artistas extranjeros que trabajan en México, tratando de entender el porqué del rechazo hacia la obra de estos, y de este artista en particular.

\section{Resultados}

\section{El contexto histórico de la obra de Mathias Goeritz en México}

La crisis de la Iglesia católica posterior a la Segunda Guerra Mundial formulaba la emergencia de lo nuevo, manteniendo la tradición. Después de la guerra, muchos países quedaron devastados y con cuantiosas pérdidas de vidas, lo que originó un replanteamiento general sobre el ser y su existencia; sobre los valores, las reglas, las tradiciones, la sociedad, la política, la fe y el arte. En México, la Iglesia católica no fue ajena a estos planteamientos, así que en ocasiones esta recuperación fue por medio de intervenciones realizadas por artistas que gozaban de un lugar especial dentro de las artes, artistas innovadores con planteamientos radicales, que en algún momento fueron transgresores del medio artístico y que viajaban entre el pasado y el futuro haciendo coincidir polos opuestos, generando nuevos significados; figuras representativas a las que la Iglesia les ha apostado para la revitalización de su patrimonio. Para ello, se buscaron intervenciones contemporáneas que no rompieran con el pasado, sino que su autor creara un vínculo que permitiera la conexión entre el pasado y el presente, con la idea de revitalizar en especial a los templos (Huidobro, 2014).

A mediados del siglo XX, preámbulo de modernidad (expresión cultural de la modernización en México), algunos edificios religiosos coloniales fueron intervenidos con un nuevo lenguaje plástico, lo que ayudó a reforzar la idea de la renovación litúrgica que se estaba gestando en el seno de la Iglesia de México. Una de las figuras más relevantes de la transformación de la Iglesia mexicana del siglo XX fue el doctor y sacerdote Sergio Méndez Arceo, simpatizante de la Teología de la Liberación, quien buscó un nuevo discurso para la Iglesia por medio de la integración de elementos modernos en la Parroquia de la Asunción (Catedral de Cuernavaca), en 1959. Cambios que primeramente se dieron en Cuernavaca y en la Purísima de Monterrey, y, posteriormente, en la parroquia de San Lorenzo Mártir (Figura 2); estos fueron los antecedentes para las intervenciones en la Catedral Metropolitana, el templo de Santiago Tlatelolco y el templo de Azcapotzalco en la Ciudad de México. Estas intervenciones, con inserciones de elementos modernos, que para algunos grupos enriquecieron a los templos antiguos y dieron un nuevo aspecto a las edificaciones, recibieron críticas de otros grupos y artistas con diferentes ideas con respecto a la forma correcta de intervenir un monumento histórico (Huidobro, 2014). 
Mathias Goeritz fue un escultor de origen polaco alemán que llegó a México en 1949, y en palabras de quien fuera su esposa, la doctora Ida Rodríguez Prampolini, fue muy mal recibido: "México es un país discriminador de extranjeros. Si son famosísimos se les recibe muy bien. Pero si no, siempre se les ataca" (entrevista con Ida Rodríguez Prampolini, en Méndez-Gallardo, 2014 , p. 19). En particular, los muralistas mexicanos atacaron terriblemente a Mathias. Diego Rivera lo acusó de ser nazi, homosexual, pervertidor de los jóvenes mexicanos. Momento crucial del nacionalismo mexicano para el cual Diego era el patriarca, muy poderoso, aún más que Siqueiros. Esta aversión se debía al hecho de que consideraban que el trabajo de Mathias era un tipo de arte que no acababa de ser abstracto. Goeritz creía en la libertad de expresión de cada persona. Entre sus actividades más importantes se encuentra el trabajo con el arquitecto mexicano Luis Barragán, quien nunca le dio crédito, y con el cual terminó enemistado a pesar de ser compadres. Sin embargo, decía, que México no era un país sino un vicio, y que no podía irse de aquí, a pesar de tener muchos amigos en Estados Unidos. Incluso de sus alumnos obtuvo poco reconocimiento, y todo ello por el hecho de ser extranjero (Méndez-Gallardo, 2014).

Nacido en el seno de una familia protestante, Mathias Goeritz fue autor de una gran cantidad de piezas religiosas que responden a credos distintos. Esta gran necesidad espiritual le permitió crear ámbitos de recogimiento e introspección que propiciaban la búsqueda de lo trascendente (Torres y Méndez-Gallardo, 2014). No solo fue pintor y escultor, sino también diseñador, arquitecto y maestro de arquitectos. Sobresalió por su convicción de que el arte modifica y reivindica al hombre. Se refiere que más que encasillarlo en una corriente artística, habría que reconocerlo en su necesidad de transformar de forma constante su visión y su quehacer artístico, bajo una actitud ética, guía trascendente de su personalidad (Torres y Méndez-Gallardo, 2014).

Con otros artistas europeos de su época, compartió el desencanto; fue testigo de las crisis de utopías y de fe; de la disgregación de los grandes sistemas. Se introdujo en la historia del arte, disciplina que le permitió conocer la estética de diferentes épocas y latitudes y, al mismo tiempo, le permitió identificarse con corrientes de vanguardia como el expresionismo, el movimiento Dadá y la Bauhaus (Torres y Méndez-Gallardo, 2014). Cabe mencionar que, paralelamente, el arquitecto alemán Hannes Meyer, que fue director de la Bauhaus, y que en 1939 llegó a México lleno de ideas arquitectónicas y urbanísticas revolucionarias, nunca logró realizar alguna tarea trascendental, a pesar del apoyo gubernamental del cual gozó, ya que fue fuertemente agredido por el gremio de arquitectos mexicanos.

\section{Los vitrales de Mathias}

Una vez terminado su contrato de tres años con la Escuela de Arquitectura de la Universidad de Guadalajara, Goeritz se traslada a la Ciudad de México, donde tiene la oportunidad de participar en la construcción o renovación de varias iglesias, producto del crecimiento demográfico urbano, lo que le permitió a Mathias, profundo creyente, un campo de trabajo donde podía desarrollar su inquietud de poner el arte al servicio de la religiosidad. En 1954, el arquitecto Ricardo de Robina y el padre Ertze Garamendi, lo invitaron a colaborar en la restauración de la parroquia de San Lorenzo, un edificio virreinal del siglo XVII en el centro de la Ciudad de México. Allí diseñó un relieve de cemento en el muro localizado a espaldas del altar (Figura 3), un vitral para el espacio sobre el coro de la iglesia y siete vitrales de la cúpula de influencia morisca (Figuras 4 y 5). Se considera que el diseño de sus vitrales se orientaba a satisfacer las necesidades de un mundo espiritual, y sus obras expresaban las inquietudes religiosas en forma anónima y con gran humildad, como se hace en una oración (Ibarra, 2009).

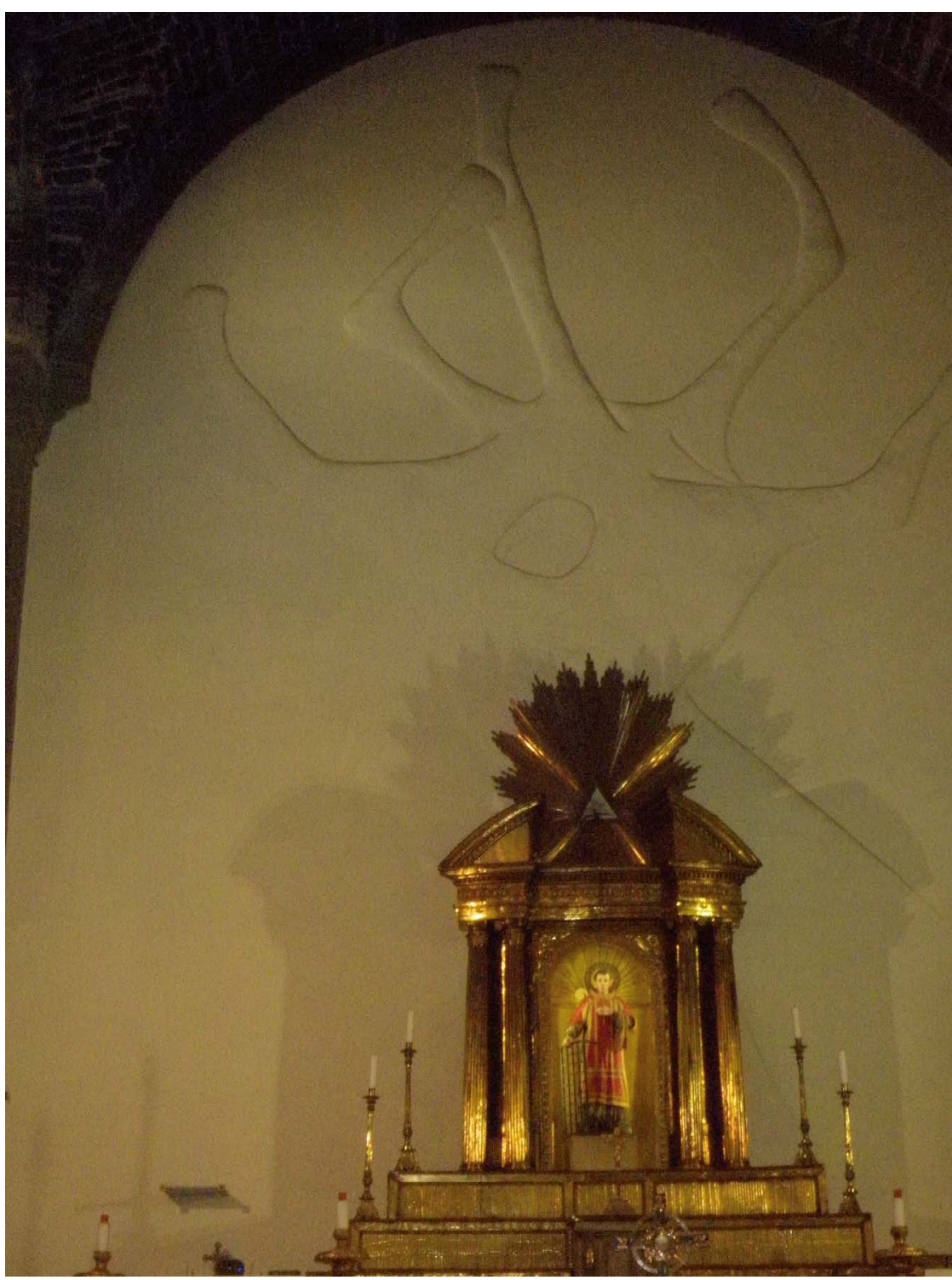

(A) Figura 3. Relieve de cemento en el muro localizado a espaldas del altar, en la iglesia de San Lorenzo Fuente: Cedeño, 2018. 


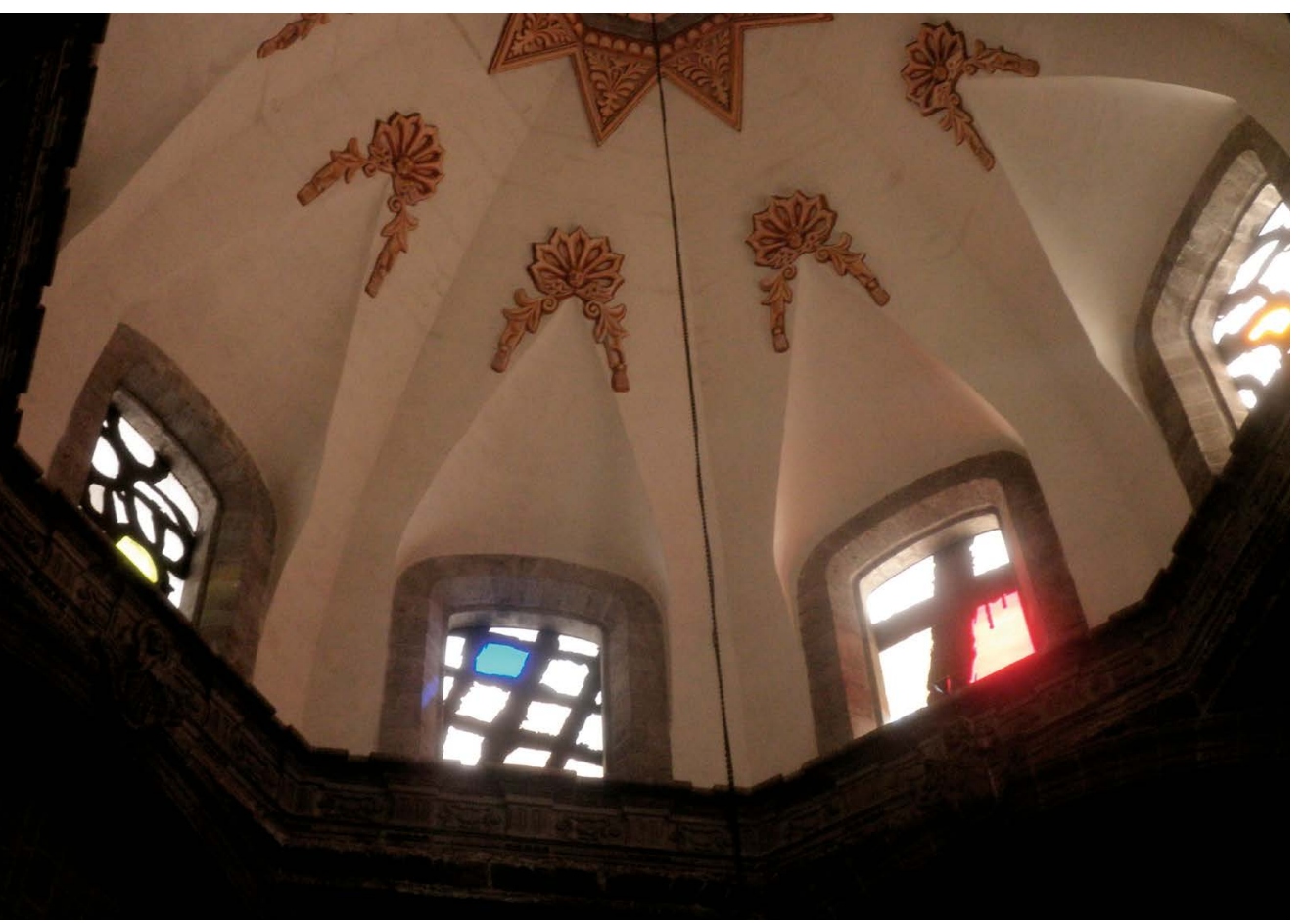

(A) Figura 4. Vistade la cúpula de San Lorenzo, donde se encuentran los vitrales más interesantes de influencia morisca Fuente: Cedeño, 2018.

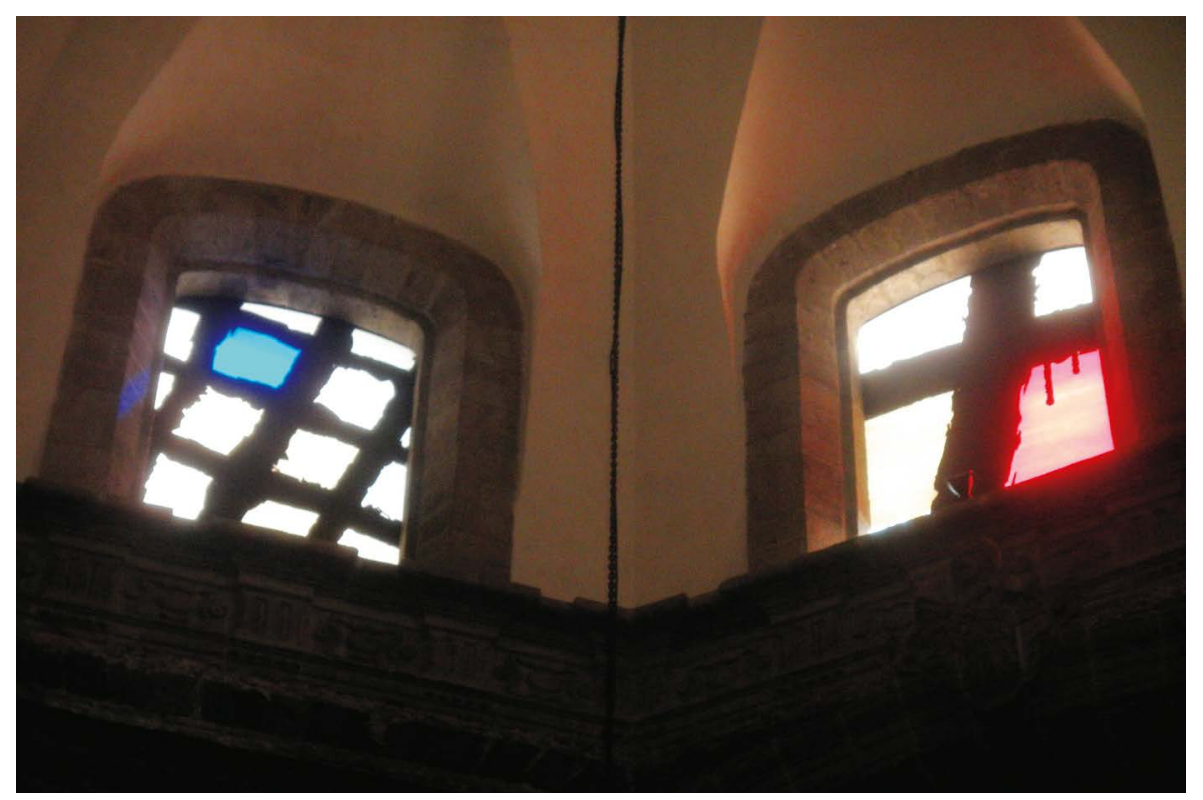

(A) Figura 5. Foto de dos de los vitrales de influencia morisca que se encuentran en la cúpula de San Lorenzo Fuente: Cedeño, 2018.
En 1960, y por invitación del arquitecto Robina, Mathias Goeritz inició los trabajos de

\begin{abstract}
.los vitrales que la Comisión de Orden y Decoro le encargó para la Catedral Metropolitana de la Ciudad de México, labor que duró seis años. El artista [...] antes había participado [...] con el arquitecto Luis Barragán en la Capilla de las Capuchinas Sacramentarias, en Tlalpan (Rodríguez y Torres, 2011).
\end{abstract}

Posteriormente se incorporaron a la obra las seis vidrieras de color ámbar en las que se aprecian formas abstractas (Figura 6). El resultado final fueron 134 vidrios de color ámbar para la nave principal, cuatro morados en la cúpula y cuatro rojos en la entrada. "El resultado fue una iluminación en el espacio interior que resaltaba el dorado de los altares y una atmósfera que propiciaba el recogimiento de los creyentes y su encuentro con la divinidad" (Ibarra, 2009, p. 71).
Dos años más tarde, se desató una fuerte campaña en contra de los novedosos ventanales, al grado que para 1966 la Secretaría del Patrimonio Nacional dio un plazo de un año para el retiro total de los vitrales y su reemplazamiento por vidrieras de manguetería reticular y vidrio incoloro con diseño aprobado por las autoridades (Rodríguez y Torres, 2011).

En 1966 se publicaba que serían retirados los "horribles adefesios" o ventanales a go go de la Catedral Metropolitana (como los llamó el arquitecto Agustín Piña), dignos de un cabaret, y que sería un error muy grave permitir que en un monumento tan respetable como es la catedral de México se exhibieran tales ventanales (Ibarra, 2009), ya que estos gustos ultramodernistas distorsionaban el sentido estético y funcional del Templo Católico Mayor de México. Aún más, la Secretaría de Patrimonio Nacional, apoyando esta idea, argumentaba que las formas irregulares de los vitrales desvirtuaban las líneas neoclásicas de Manuel Tolsá. De 1961 a 1966, se presentaron argumentos de especialistas sobre lo inapropiado de los vitrales de Mathias Goeritz, y sobre cuál debería ser la solución para sustituirlos (Rodríguez y Torres, 2011).

No obstante estas críticas, Mathías recibió varias invitaciones para colaborar en la renovación de iglesias coloniales, como la que le hizo el polémico obispo Sergio Méndez Arceo para la catedral de Cuernavaca, donde colocó vidrios teñidos que armonizaron con las grandes pinturas del templo que muestran el martirio de los misioneros mexicanos en Japón. También colaboró en la renovación de la iglesia dominica de Azcapotzalco (1961-1962) y la de Santiago Tlatelolco en la Plaza de las Tres Culturas (Ibarra, 2009).

La doctora Ida Rodríguez Prampolini, esposa en ese entonces de Goeritz, envió una carta al diario Excelsior donde contradecía cada uno de los argumentos expuestos por los especialistas:

\footnotetext{
. a su amigo y maestro el doctor de la Maza le cuestionó que si es más adecuado hacer réplicas del pasado, entonces el arte moderno es incapaz de aportar valores artísticos religiosos a la Catedral como en otras épocas lo hicieron artistas de su tiempo. Al arquitecto González Galván le reprochó haberse expresado sobre los vitrales de color rojo como "una porquería", argumentando que esta aseveración mostraba "una forma de expresión antiestética y lamentable para un miembro del Instituto de Investigaciones Estéticas de la UNAM". Al doctor Antonio Bodet simplemente le aclaró que las ventanas que se estaban reemplazando se montaron sobre perfiles modernos, así que no se estaban destruyendo objetos valiosos (Rodríguez y Torres, 2011).
}

Se determinó como plazo para el retiro total de los vitrales el mes de septiembre de 1967. Sin embargo, un desastroso incendio destruyó parte de la obra de Goeritz, entre otras obras importantes, como la sillería del coro que tarda- 


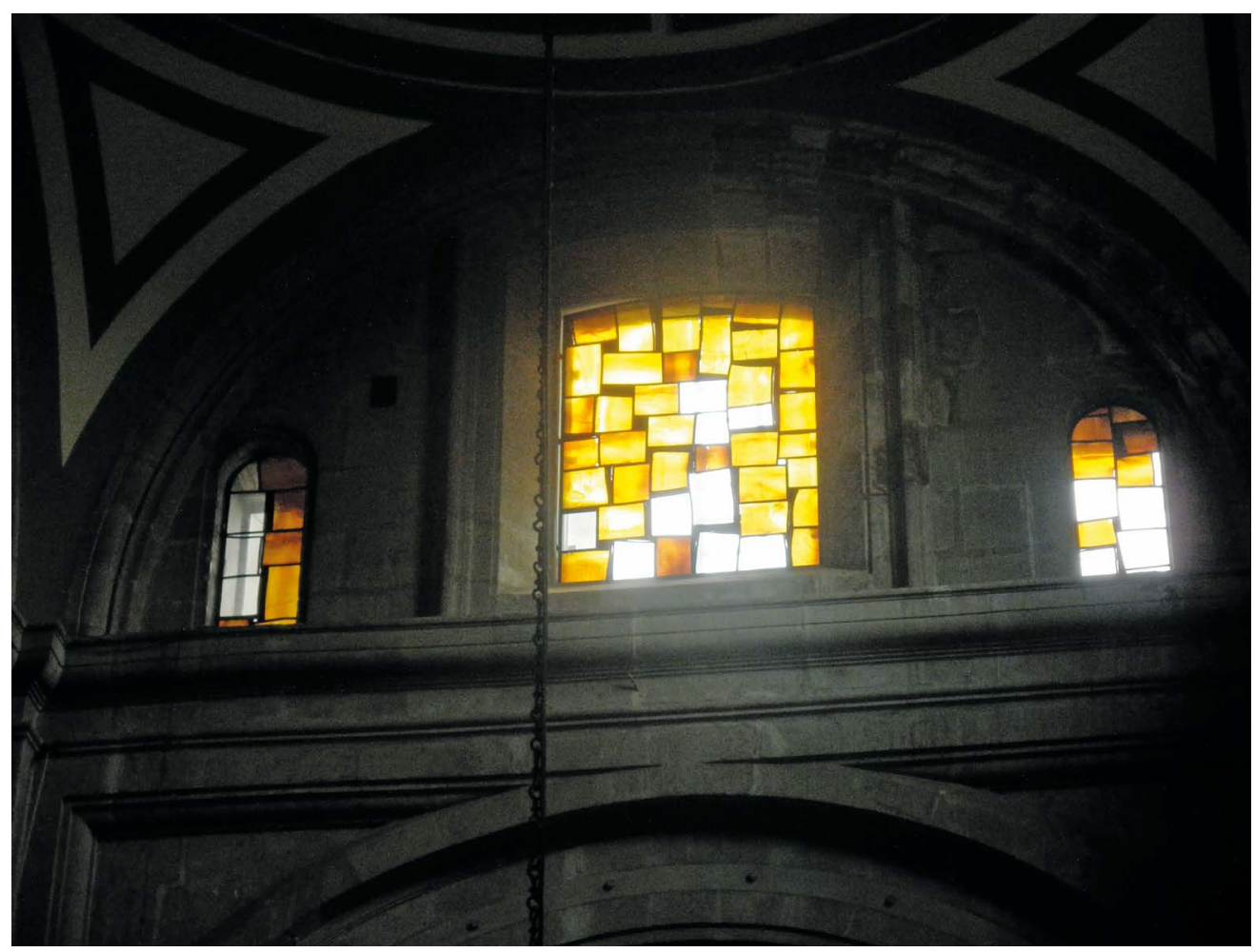

\&igura 6. Detalle de uno de los vitrales que se encuentran en la Catedral

Fuente: Cedeño, 2015.

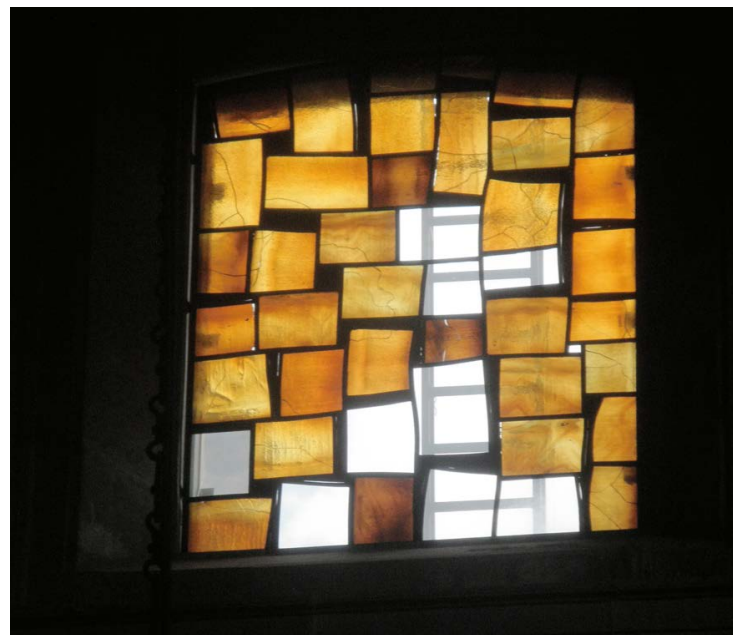

(A) Figura 7. Detalle de algunos de los vitrales de la Catedral, los cuales lograron salvarse del incendio

Fuente: Cedeño, 2015

ría años en ser restaurada (Figura 7). Ante este desastre, entre especialistas se discutió el futuro de la Catedral y surgieron así dos posturas; la de los "neobarrocos o restauradores", y la de los "modernistas y renovadores". Los personajes que conformaban cada posición eran:

El bando neobarroco estaba conformado por críticos del arte como Jorge Alberto Manrique, historiadores de la talla de Edmundo O'Gorman y Francisco de la Maza, Antonio Castro Leal, expresidente de la Comisión de Monumentos Históricos, Artísticos y Arqueológicos de la UNESCO en París, y como era de esperarse, el grupo de arquitectos encabezado por Agustín Piña Dreinhofer, entre otros. El modernista o renovador agrupó a personajes como el canónigo Ramón de Ertze, el obispo de Cuernavaca Sergio Méndez Arceo y el arzobispo de México Miguel Darío Miranda; la doctora y crítica en historia del arte Ida Rodríguez Prampolini y el también crítico de arte Antonio Rodríguez, como también los arquitectos Mario Pani, Ricardo de Robina y Enrique del Moral, entre los más polémicos (Rodríguez y Torres, 2011).

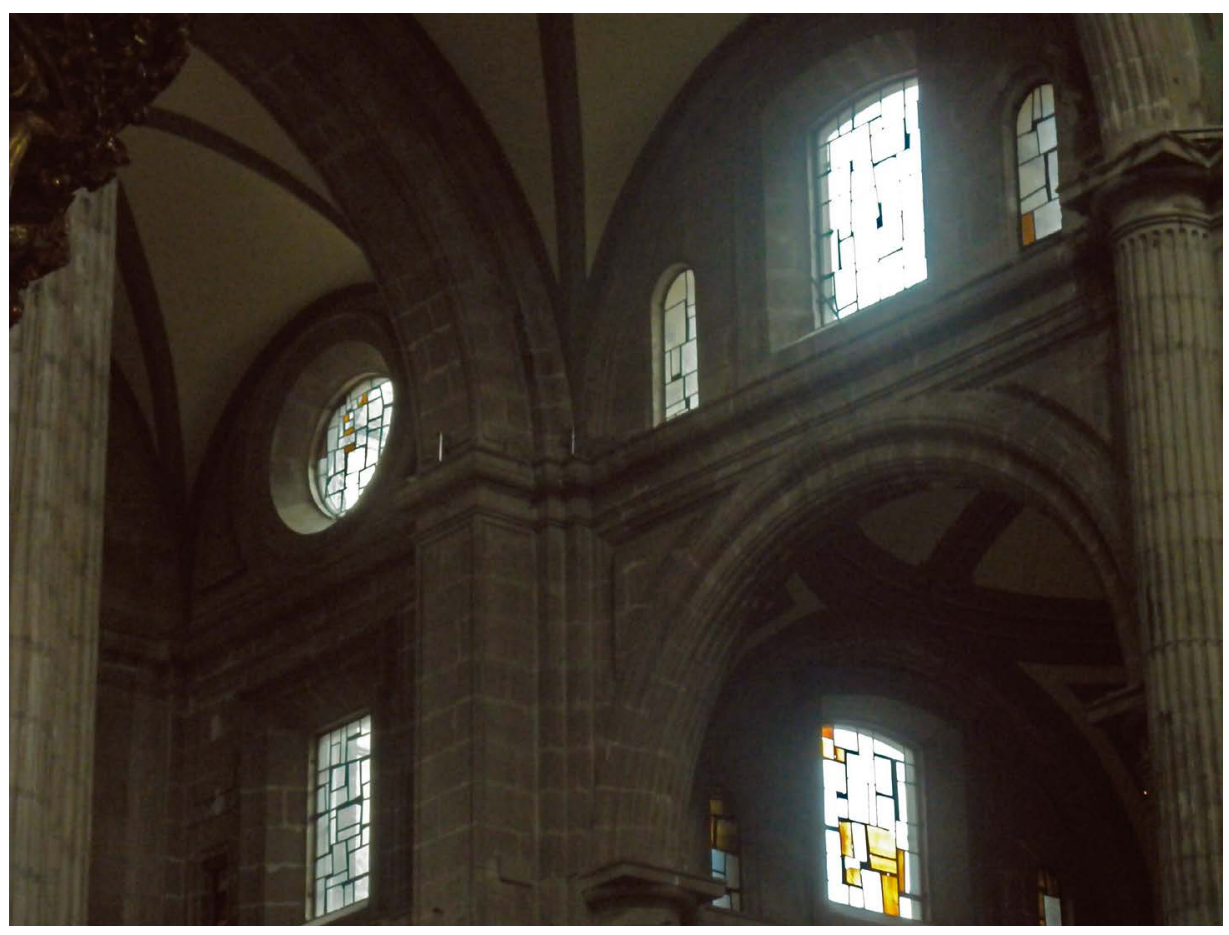

En 1990, meses antes de la muerte de Mathias, la Asociación Amigos de la Catedral Metropolitana anunció la asignación de 690 millones de pesos para retirar la obra restante de Goeritz.

Esto provocó que se levantaran fuertes protestas en contra del desmantelamiento de los vitrales por parte de investigadores e historiadores del arte como Graciela Schmilchuk, Francisco Reyes Palma, Ida Rodríguez Prampolini, Jorge Alberto Manrique y Lily Kassner, así como artistas, tales como la escultora Helen Escobedo y el arquitecto Ricardo de Robina (Rodríguez y Torres, 2011).

En 2004, la Dirección General de Sitios y Monumentos del Patrimonio Cultural del Consejo Nacional para la Cultura y las Artes realizó un "Proyecto para las ventanas de la Catedral Metropolitana de México", donde determinó que se reconocían 98 vitrales de los 134 puestos originalmente y destruidos en el incendio,
A Figura 8. Interior de la Catedral. Se observa cómo se ven en la actualidad los vitrales realizados por Mathias Goeritz

Fuente: Cedeño, 2015 
algunos sismos, los continuos hundimientos, la falta de un mantenimiento preventivo periódico, además de las obras de corrección geométrica y rehabilitación estructural del inmueble que se realizaron de 1989 a 2000. El director general, Xavier Cortés Rocha, visitó al hijo de Mathias, Daniel Goeritz, y a la propia Ida Rodríguez para comunicarles esta decisión, ante lo cual Ida Rodríguez escribió:

La Catedral Metropolitana tiene estilos de varias épocas [...] ¿Por qué nuestro tiempo no puede dejar su huella también? ¿Por qué se empeñan siempre en destruir lo que está probado mundialmente que es muy bello y que produce un ambiente de recogimiento místico? Se ha dicho que la luz ámbar no tiene buen efecto sobre el Altar de los Reyes. A mi juicio y el de muchos historiadores de arte nos parece lo contrario. La luminosidad resalta la belleza del bello altar. Pido más cuidado y respeto para una obra considerada mundialmente como un gran acierto. México está en deuda con Goeritz, basta recordar que sus Torres de Ciudad Satélite ahora aparecen como diseñadas por el arquitecto Luis Barragán. Muchas obras del creador de la arquitectura emocional, como El Eco, y del minimal art han sido destruidas.

Con Ida Rodríguez se sumaron [...] quienes en la prensa dejaron sentir su enérgica protesta, ya que para ese entonces el artista había muerto y por tanto se había revalorado históricamente su obra en la Catedral como aportación artística del siglo $X X$ y, por lo tanto, patrimonio de la nación ya en el siglo XXI (Rodríguez-Torres, 2011).

Los vitrales de la Catedral han logrado subsistir, y todo parece indicar que debido al aniversario del nacimiento del artista en el 2015, y la publicación de un libro sobre el tema, se fortaleció la idea de su preservación (Figura 8).

Estos problemas existentes con la conservación de los vitrales de Goeritz ponen en evidencia que en México no se cuenta con ningún tipo de protección normativa ni artística. En la búsqueda de una futura protección patrimonial de estos y otros vitrales contemporáneos, se debe primeramente tratar de comprender aquello califica a una obra de arte como tal; de esta manera se puede entender la importancia de que estas queden protegidas bajo el marco de la evolución de las disciplinas, áreas de conocimiento y conceptos internacionales relacionados con la protección de los monumentos y del patrimonio cultural en general. De igual importancia es la inclusión de las leyes mexicanas dedicadas a la conservación del patrimonio.

\section{El ser humano y la obra de arte}

Lo expuesto con anterioridad respecto a cualquier obra de arte, trátese de un artista nacional o extranjero, remite a la pregunta: ¿cómo se ha dado la relación entre los seres humanos y las obras de arte que estos han creado? Particularmente, Ceschi (1970), uno de los brillantes alumnos de Gustavo Giovannoni y uno de los grandes restauradores italianos del siglo $\mathrm{XX}$, refiere que la obra de arte de alguna manera existe si quienes la han heredado, es decir, la hace existir para sí y para los demás, esto le da un reconocimiento creándola dentro de sí, haciéndola revivir espiritual y culturalmente, de acuerdo con su forma de pensar y de sentir. De esta manera, la obra de arte tiene gran influencia en los seres humanos de un determinado periodo de la historia. Esta influencia ha cambiado continuamente la sensibilidad de la humanidad y, en consecuencia, su relación con las obras del pasado y con el pasado mismo. En este sentido, se refiere que cada época, en efecto, ha tenido una forma particular de ver el pasado, procediendo de acuerdo con una decisión general, apoyándo o renegando, aceptando imposiciones o sugerencias, o liberándose totalmente de estas sugerencias, pero siempre estableciendo relaciones de muy diverso tipo (Ceschi, 1970). Esto significaría que el reconocimiento de los mexicanos sobre la obra de Goeritz y otros artistas extranjeros dependería de la propia percepción que estos mismos tienen de las obras.

Por una falta de visión histórica del pasado, la relación hombre-obra de arte es imprecisa, mutable, arbitraria, y cuando los arquitectos se relacionan con un edificio para readaptarlo a las nuevas exigencias, o para sustituir alguna de sus partes, o para completarlo, es siempre el monumento el que debe entrar en la visión del arquitecto y nunca lo contrario (Ceschi, 1970, p. 13).

Es preciso entender la importancia de que una sociedad reconozca una determinada obra de arte. Precisamente, aquí debemos cuestionar el papel del arquitecto que, al margen de los demás participantes de una sociedad como la mexicana, considera tener una opinión más autorizada para evaluar "aquello que vale", y poder emitir una crítica sobre las partes de un inmueble histórico que "no valen la pena". Sin embargo, otra pregunta relevante surge: ¿qué otorga a una obra de arte este calificativo? De acuerdo con Brandi (1977), gran teórico de la restauración, una obra de arte lo es por el hecho de contar con un reconocimiento doblemente personal que se da en la conciencia, ya sea por el hecho de haber sido terminada por un único individuo, ya sea por el reconocimiento que se otorga al mismo individuo. El producto humano reconocido se encuentra frente a nuestros ojos, pero podría clasificarse genéricamente como un producto de la actividad humana. De ahí que el reconocimiento que en la conciencia individual se hace como obra de arte, no lo exceptúa de una coincidencia con otros productos de la actividad humana. Esta es la característica peculiar de la obra de arte en cuanto no se interroga su esencia ni el proceso creativo que la ha producido, dado que entra a formar parte del mundo particular de cada individuo (Brandi, 1977); esta opinión refuerza la de Ceschi (1970).

Brandi (1977) refiere que en una obra de arte no es tan importante qué tan antigua y qué tan clásica es, sino que en la actualidad, y no solo potencialmente, una obra de arte es en cuanto vive en cualquier experiencia personal; en cuanto debido al material que la constituye permanece 
idéntica a través de los años, pero como obra de arte es recreada cada vez que es experimentada estéticamente. Lo anterior significa que hasta que la recreación o el reconocimiento no suceda, la obra de arte es solo tal potencialmente: no existe sino subsiste; es solo un trozo de mármol, de tela (Dewey, 1939, en Brandi, 1977, pp. 4-5). Para Giovanni Carbonara, Brandi acentúa la preponderancia de la instancia estética como expresión de las razones de aquello que hace a la obra de arte como tal (1976, pp. 74-75). De acuerdo con estas opiniones, a los mexicanos nos corresponde decidir si estos trabajos los reconocemos como obra de arte o no.

Para Fernández Arenas (1972), una obra de arte es aquella actividad intelectual y creativa elaborada por el hombre con la finalidad de transmitir sensaciones, conocimientos y valores. Las características de estas obras de arte serían: originalidad, autenticidad, unicidad-singularidad, comunicabilidad y artificialidad (Fernández, 1972). Pensamos que la obra de Goeritz cumple perfectamente con estas características.

El gestor cultural colombiano Manuel Drezner (2015), en su texto Explorando el arte: cómo mirar y entender un cuadro, señala como elementos básicos: la inspiración del artista y las técnicas que este usó, la perspectiva, la combinación de colores y la composición. Importante también es el contexto histórico que la rodea (El Universal, 2015, junio 11).

De acuerdo con criterios modernos sobre cómo juzgar una obra de arte, pensamos que la obra de Goeritz no tendría por qué ser cuestionada; sin embargo, para que esta gozara de una protección legal que impidiera su destrucción, tendría que ser reconocida como monumento artístico, así que enseguida se explorarán las posibilidades de que esto sea así.

\section{La protección legal de los vitrales}

La conservación del patrimonio artístico en la legislación mexicana se puede inscribir como parte de la propiedad intelectual, que Ernesto Becerril (2003) define como:

\begin{abstract}
... el conjunto de bienes y manifestaciones actuales, producto de la creación de uno o varios individuos, a través de su sola acción o en conjunto con la naturaleza, que por contener una serie de valores intelectuales, científicos, técnicos, estéticos o sociales, son objeto de protección y reconocimiento especial a favor de los creadores por parte del Estado a fin de evitar su ilegal utilización o reproducción (p.18)
\end{abstract}

En este sentido, en México, la Ley Federal Sobre Monumentos y Zonas Arqueológicos, Artísticos e Históricos, de 1972, clasifica a los monumentos como arqueológicos, históricos y artísticos.

Son monumentos arqueológicos los bienes muebles e inmuebles, producto de culturas anteriores al establecimiento de la hispánica en territorio nacional, así como los restos humanos, de la flora y de la fauna, relacionados con estas culturas [...]
Son monumentos artísticos, las obras que revisten valor estético relevante. Salvo el muralismo mexicano, las obras de artistas vivos no podrán declararse monumentos [...]Son monumentos históricos los bienes relacionados con la historia de la nación, a partir del establecimiento de la cultura hispánica en el país, a partir de los términos de la declaratoria respectiva o por determinación de la Ley (Ley Federal de 1972, arts. 28, 33 y 35).

Por tanto, los vitrales, y de manera particular la obra de Mathias Goeritz (Figura 9), de acuerdo con la Ley Federal de 1972, cabe perfectamente en la definición de patrimonio artístico. Becerril (2003) menciona que la protección de un determinado grupo de bienes, que tienen un valor cultural reconocido, impone la necesidad de establecer un régimen jurídico especial que permita la obtención de este fin. Para ello se hace un examen para la posterior aceptación por parte de la autoridad de la importancia histórico-artística de un mueble, inmueble o zona. Con tal fin, la autoridad debería establecer una "escala de valores histórico-artísticos" que le permitan a tal objeto ingresar dentro de la normatividad. Es importante que el bien en cuestión sea representativo o contenga una significancia para el grupo social; de lo contrario, la preservación del mismo no cumplirá con los requisitos esenciales para la protección de estos bienes, pues su relevancia no será aceptada por toda la sociedad. La determinación de estos valores por parte de los órganos gubernamentales puede ser muy cuestionable, y la consecuencia es la desprotección de gran parte de nuestro legado cultural (p. 72). Enrique Florescano (1993) pone el acento en "que la selección de bienes y testimonios culturales es realizada por los grupos sociales dominantes, de acuerdo con criterios y valores no generales, sino restrictivos o exclusivos" (citado por Becerril, 2003, p. 72); cuando el Estado nacionalista presenta una selección, esta es de acuerdo con los "intereses nacionales" del grupo hegemónico, que no siempre coinciden con los intereses reales de la nación.

En conclusión, se establece que el valor histórico-artístico de un mueble, inmueble o zona tendrá que basarse en una serie de criterios objetivos que deben de estar incluidos en la legislación, a fin de instrumentar un adecuado régimen jurídico que permita la protección de aquellos bienes que efectivamente sean relevantes, a través de procedimientos que promuevan la participación de los especialistas en esa materia (Becerril, 2003, p. 73). De acuerdo con Becerril, la diferencia entre los bienes históricos y los monumentos artísticos estriba en la inclusión de un valor estético relevante, en el desarrollo evolutivo del país en cuestión. Este valor debe responder a "las siguientes características: representatividad, inserción en determinada corriente estilística, grado de innovación, materiales y técnicas utilizadas y otras analogías". ${ }^{1}$

1 Ley Federal de Protección al Patrimonio Inmaterial y Material de la Nación, artículo 42. Recuperado de http://cronica.diputados.gob.mx/DDebates/61/2do/2P/Ord/mar/00L61A2P210. html 


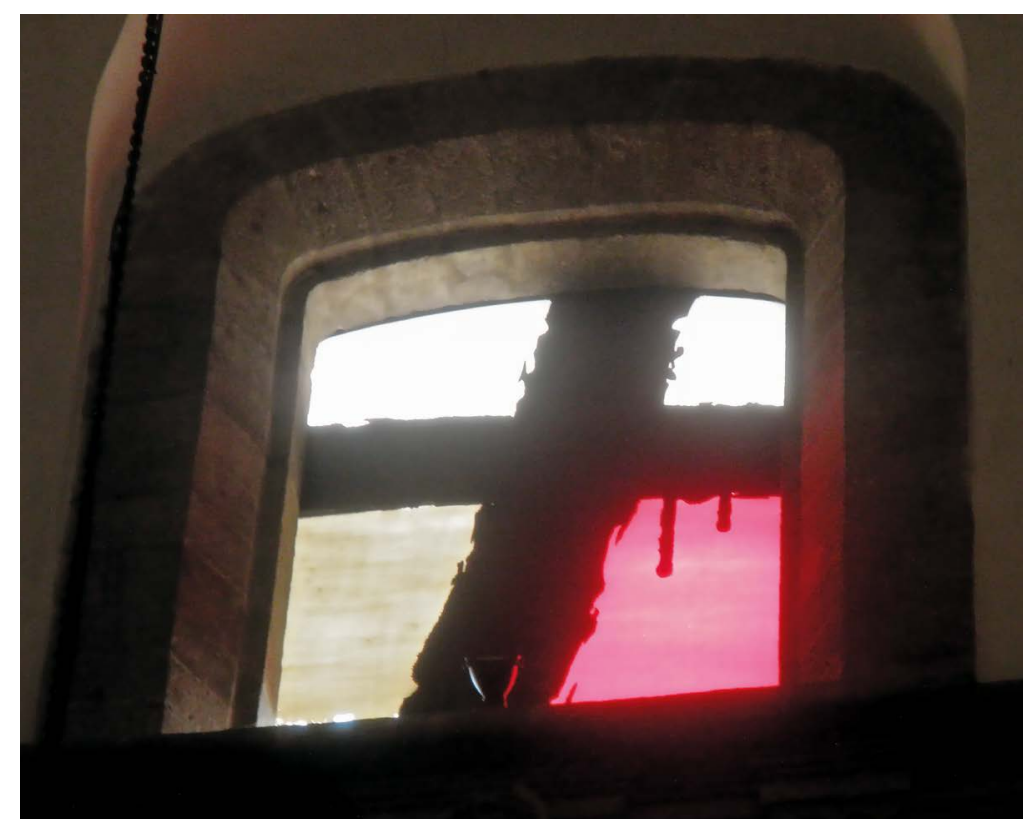

(A) Figura 9. Detalle de uno de

los vitrales que se encuentran en

San Lorenzo

Fuente: Cedeño, 2018.

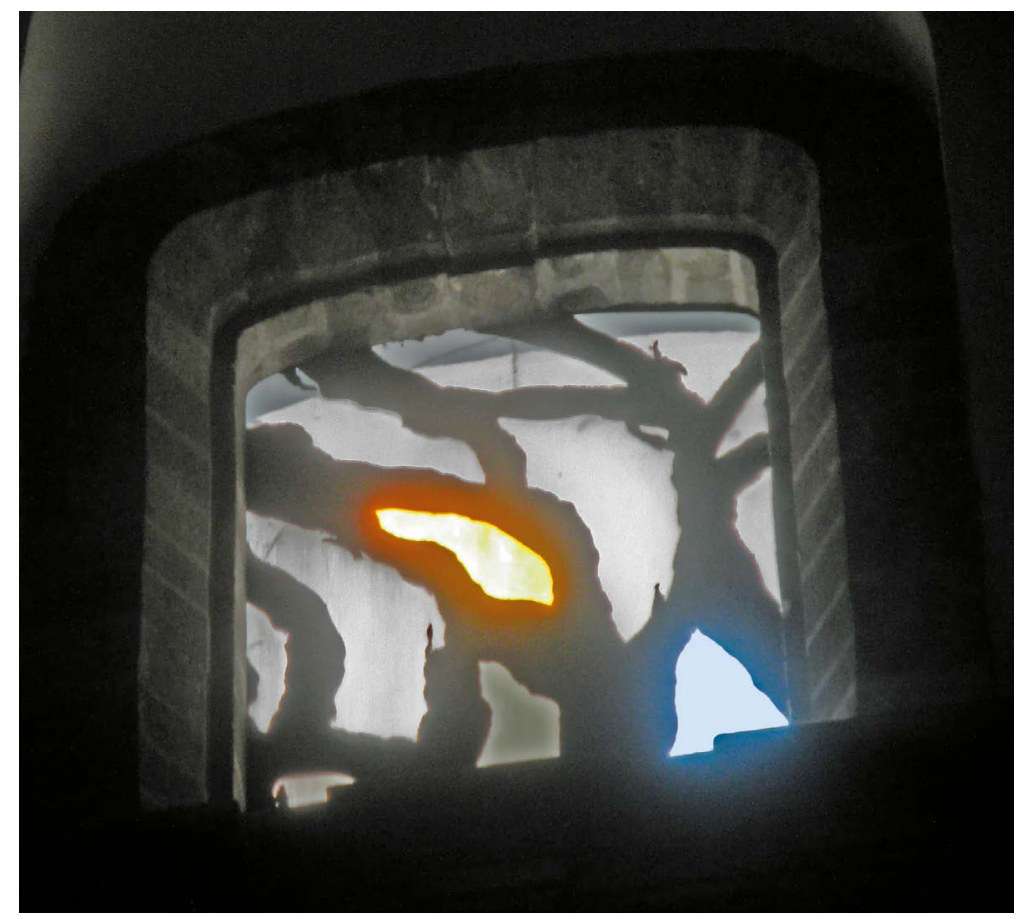

A Figura 10. Otro de los vitrales de la cúpula Fuente: Cedeño, 2018.
Cuando se trate de artistas extranjeros, solo podrán ser declaradas como monumentos las obras producidas en territorio nacional. La declaratoria de monumento podrá comprender toda la obra de un artista o solo parte de ella. Se define que un error frecuente en México es considerar como monumentos históricos los anteriores a 1900 y artísticos los monumentos posteriores a esta fecha (Becerril, 2003).

Finalmente, se señala que las leyes mexicanas definen dos posibilidades para que un bien ingrese al sistema de protección del patrimonio histórico artístico: una puede ser por ministerio de ley, y la otra consiste en aquellos monumentos y zonas que propiamente son declaradas como tales. En el primer caso, tal y como sucede para los vitrales y la obra de Mathias Goeritz (Figura 10), un inmueble o mueble puede ser monumento por simple ministerio de ley, entendiéndose esta locución como el hecho de que, sin necesidad de declaración alguna por parte del órgano estatal, se producen instantáneamente los efectos y las consecuencias dispuestas por la norma jurídica. En esta categoría entrarán los monumentos arqueológicos y los monumentos históricos artísticos (comprendidos en las fracciones I, II y III del artículo 36 de la Ley Federal Sobre Monumentos y Zonas Arqueológicos, Artísticos e Históricos), cuyos términos se refieren a lo "relevante", a la "rareza" y la "importancia" para determinar el carácter de monumento histórico de ciertos bienes. Tal postura o marco legal ha sido criticada ya que se considera que es ambigua y restringe la propiedad de otros (Becerril, 2003), por tanto, y del mismo modo, siguen sin considerarse así los propios vitrales de Mathias Goeritz en la Catedral Metropolitana de la Ciudad de México.

\section{Consideraciones finales}

Es innegable que la labor del Estado en México por implantar un fuerte nacionalismo en el pueblo, como consecuencia de los logros de la Revolución mexicana después de 1917, crearon en los mexicanos un fuerte rechazo hacia lo extranjero. Bajo este marco sociocultural patrimonial, desde entonces a la obra de Mathias Goeritz, a pesar de ser estéticamente muy valiosa, y cumplir con los requisitos que impone ser calificada como tal, no se le ha valorizado y dado el estatus adecuado para designarla como patrimonio artístico, lo que le otorgaría una protección contra cualquier intento de destrucción. Es importante destacar la necesidad de que las personas hagan suya esta obra a fin de que, como lo establecen Ceschi y Brandi, no haya duda sobre su calificación como obra de arte, para una posible catalogación, la cual le otorgaría una real protección.

Desde el punto legal, la diferencia entre los bienes históricos y los monumentos artísticos estriba en la inclusión de un valor estético relevante que debe responder a las siguientes características: representatividad, inserción en determinada corriente estilística, grado de innovación, materiales y técnicas utilizadas, y otras analogías. Desde la perspectiva de que la declaratoria de monumento podrá comprender toda la obra de un artista o solo parte de ella, los postulados del valor estético de la obra de Mathias Goeritz permiten que sea reconocida en México, a pesar de la resistencia por parte de artistas y arquitectos nacionales a reconocer la obra de estos artistas extranjeros.

Como un elemento analítico final, se recoge la crítica de la conservación de estos vitrales contemporáneos en México, realizada por Díaz-Berrío, quien refiere a la reintegración como un tipo de restitución en su sitio original de partes desmembradas del objeto, para asegurar su conservación, y en este sentido existe una identificación con 
la anastilosis. También se refiere a la integración como la aportación de elementos claramente nuevos y visibles para la conservación del objeto; elementos que son introducidos, no en función de un simple reforzamiento estructural y, por tanto, idealmente escondidos a la vista, lo cual se nombraría como consolidación, sino con la finalidad de asegurar la conservación del objeto que resulta ser propiamente un concepto más amplio. Sin embargo, a pesar de aceptar en la integración elementos claramente nuevos y visibles (Díaz-Berrío, 1986) critica cualquier acto creativo, es decir, intervenciones neutras. En contradicción, Carbonara (1976) menciona que las intervenciones neutras no existen, ya que cada modificación tiende siempre a crear nuevas relaciones visibles con el entorno. La idea de Díaz-Berrío en este sentido no es signo de conciencia crítica y, por ello, no afronta plenamente el problema. De ahí que es necesario afirmar con claridad la autonomía de la nueva intervención, la cual puede y debe ser actuada con el único lenguaje que ahí es permitido -aquel de nuestra época, refutando el mimetismo y la ambientación-, pero dentro del límite de caminos críticos seguros, sin que las restricciones de lo impuesto conduzcan necesariamente a una expresión no sincera o no esforzada. Se distingue que es más bien lo contrario, dificultades y restricciones estimulan la creatividad que es auténticamente tal, si se es capaz de resolverlo, sin negarlo, en la imagen. De tal forma, que no se dan casos de expresión artística sin limitaciones externas, y no solo en ambientes históricamente estratificados (Carbonara, 1976).

\section{Conclusiones}

Se puede concluir que no existen razones para que vitrales como los de Matthias Goeritz no sean reconocidos como obra de arte y posteriormente como patrimonio artístico y, por lo tanto, protegidos y conservados. Se puede presumir que el problema principal radica en lo expresado anteriormente, en el sentido de que el Instituto Nacional de Bellas Artes de México (INBA) no ha llevado a cabo la tarea que la ley le confiere en cuanto a la catalogación y, por ello, el reconocimiento de este patrimonio. Ante los nuevos escenarios planteados por la globalización y la comercialización del patrimonio a través de los medios de comunicación, parece retrógrado el seguir excluyendo manifestaciones artísticas como los vitrales contemporáneos en la Catedral Metropolitana de la Ciudad de México, mientras que en los países europeos la práctica de unir el arte contemporáneo con el patrimonio histórico es muy aceptada.

El debate sobre la conservación de los vitrales de Matthias Goeritz sigue vigente, por lo que este documento constituye un aliciente sobre la necesidad de reiterar posturas legales y culturales acordes con el reconocimiento de los distintos momentos de la historia de nuestro patrimonio material. Independientemente de los afanes nacionalistas, las obras de arte y los monumentos representan lo que se valoraba en un momento determinado, por lo que su mantenimiento y conservación hacen parte del legado de la memoria de las comunidades.

\section{Referencias}

Becerril, J. (2003). El derecho del patrimonio histórico-artístico en México. México: Porrúa.

Brandi, C. (1977). Teoria del restauro. Torino: Giulio Einaudi editore s.p.a.

Carbonara, G. (1976). La reintegrazione dell'imagine. Roma: Bulzoni Editore.

Cedeño-Valdiviezo, A. y Huidobro-Olvera, C. (2014) El gótico y los vitrales. Investigación y diseño, 10.

Ceschi, C. (1970). Teoria e storia del restauro. Roma: Mario Bulzoni Editore

Dewey, J. (1939). Art as Experience. New York: Capricorn Books.

Díaz-Berrío Fernández, S. (1986). Protección del patrimonio cultural urbano. México: Instituto Nacional de Antropología e Historia (INAH).

Drezner, M. (2015). Explorando el arte: cómo mirar y entender un cuadro. Bogotá: Yoyo Libros.

El Universal (2015, junio 11). Cómo entender y mirar una obra de arte. México. Recuperado de https:/www.eluniversal.com.mx/ articulo/cultura/artes-visuales/2015/06/11/ como-mirar-y-entender-una-obra-de-arte

Escalante, P. (2011). El patrimonio, las ruinas y nosotros. En P. Escalante Gonzalbo, La idea de nuestro patrimonio histórico y cultura tomo II). El patrimonio histórico y cultural de México (1810-2010). México: Conaculta.
Fernández Arenas, J. (1972). Teoría y metodología de la historia del arte. Barcelona: Anthropos.

Florescano, E. (1993). El patrimonio cultural de México. México: FCE.

Huidobro, C. (2014). La intervención del artista en la experiencia del espacio sacro. Integración de vitrales en templos antiguos (Tesis doctoral en proceso), México, Posgrado en Diseño, UAM, Xochimilco.

Ibarra, L. (2009, junio). Los vitrales de Mathias Goeritz. Revista Artes de México, 94, 69-72. Recuperado de https:/catalogoartesdemexico. com/productos/vitrales/

Ley Federal sobre monumentos y zonas arqueológicos, artísticos e históricos. Diario Oficial de la Federación el 6 de mayo de 1972. Recuperado de http://www.diputados.gob. mx/LeyesBiblio/pdf/131_160218.pdf

Méndez-Gallardo, M. (2014, diciembre). La obsesión por el arte. Entrevista con Ida Rodríguez Prampolini. Revista Artes de México, 115, Recuperado de https://www.artesdemexico.com/la-obsesion-por-el-arte-entrevista-con-ida-rodriguez-prampolini/

Pérez, Montfort, R. (2011). Nacionalismo y representación en el México posrevolucionario (1920-1940). La construcción de estereotipos nacionales. En P. Escalante Gonzalbo (coord.), La idea de nuestro patrimonio histórico y cultural (tomo II). El patrimonio histórico y cultural de México (1810-2010). México: Conaculta.

Rodríguez Pérez, A. M. y Torres Hernández, L. (2011, enero-abril). El silencio como estrategia de destrucción. Vitrales de la Catedral Metropolitana de la ciudad de México. Discurso visual. 16. Recuperado de http:// discursovisual.net/dvweb16/confrontacion/ confana.htm

Roselló, E. (2011). De iglesias, catedrales, capillas y conventos: paradojas y claroscuros de nuestro patrimonio cultural. En P. Escalante Gonzalbo, La idea de nuestro patrimonio histórico y cultural (tomo II). El patrimonio histórico y cultural de México (1810-2010) México: Conaculta.

Torres Hernández, L. y Méndez-Gallardo, M (2014). Mathias Goeritz. Obsesión creativa. Artes de México (Catálogo), 115. Recuperado de https://catalogo.artesdemexico.com/ productos/mathias-goeritz-1/ 


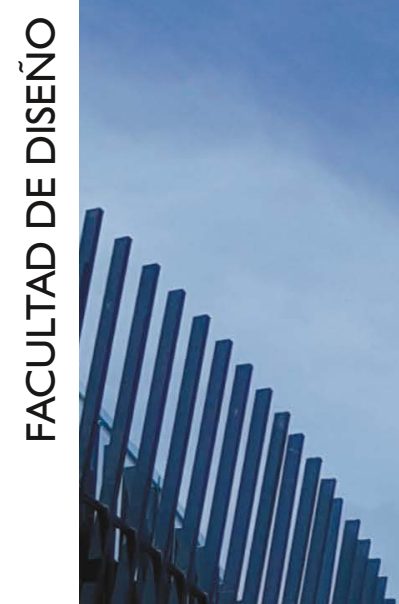

Vol.

\section{Nro. 1REVISTA DE ARQUITECTURA}
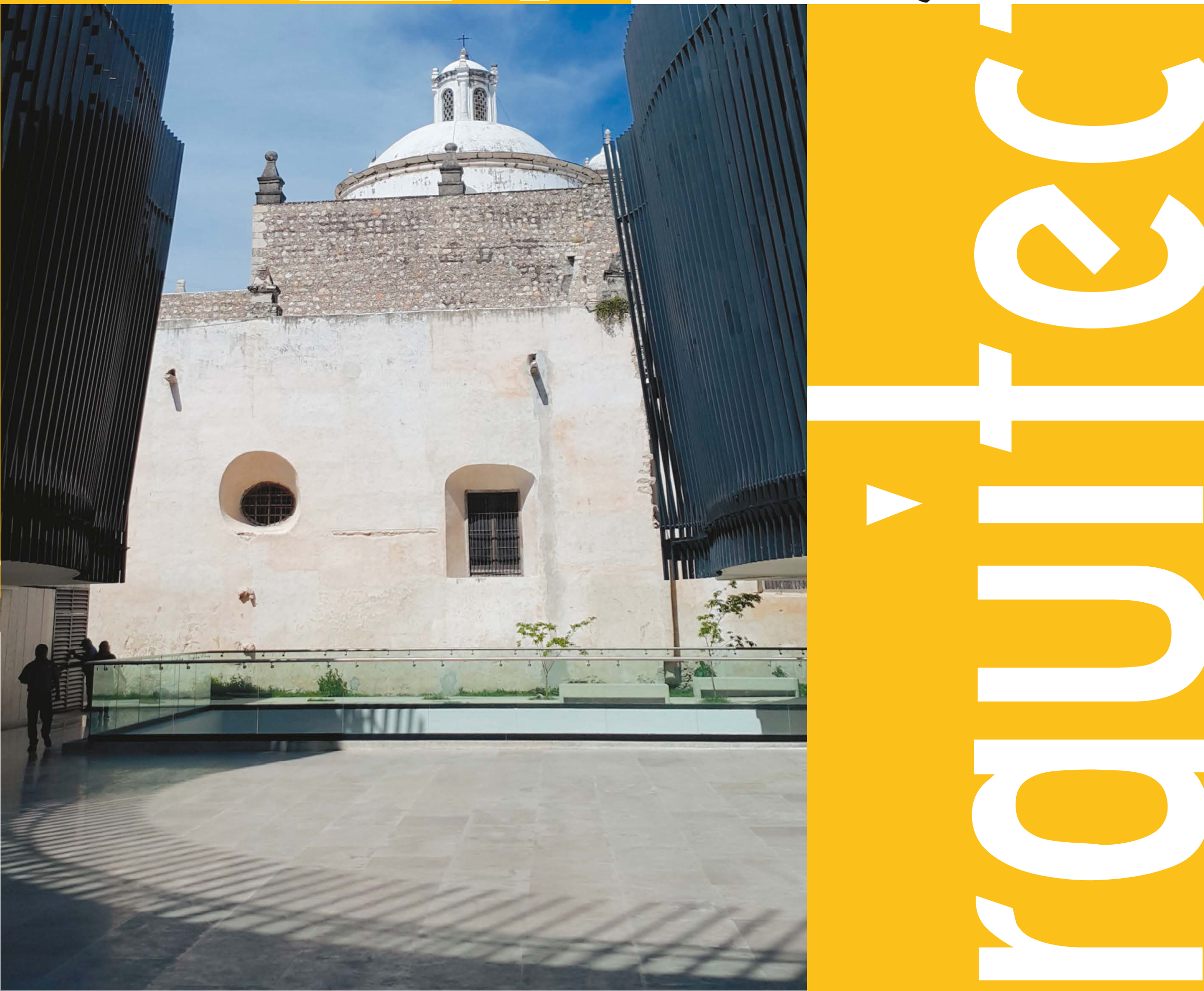
A) Portada: Palacio de la Música y Rectoria El J Júśs Tercera Orden. Mérida, Yucatán (México).

Fotografía: César Eligio-Triana (2018, septiembre) CC BY-NC

\section{(c) (1) ( $)$}

A Orientación editorial

\section{Enfoque y alcance}

La Revista de Arquitectura (Bogotá) ( (ISSN 1657-0308 Impresa y E-ISSN 2357-626X en línea) es una publicación seriada de acceso abierto, arbitrada mediante revisión por pares (doble ciego) e indexada, en donde se publican resultados de investigación originales e inéditos.

Está dirigida a la comunidad académica y profesional de las áreas afines a la disciplina. Es editada por la Facultad de Diseño y el Centro de Investigaciones (CIFAR) de la Universidad Católica de Colombia en Bogotá (Colombia).

La principal área científica a la que se adscribe la Revista de Arquitectura (Bogotá) según la OCDE es:

Gran área: 6. Humanidades

Área: 6.D. Arte

\section{Disciplina: 6D07. Arquitectura y Urbanismo}

También se publican artículos de las disciplinas como 2A02, Ingeniería arquitectónica; 5G03, Estudios urbanos (planificación y desarrollo); 6D07, Diseño.

Los objetivos de la Revista de Arquitectura (Bogotá) son:

- Promover la divulgación y difusión del conocimiento generado a nivel local, nacional e internacional

- Conformar un espacio para la construcción de comunidades académicas y la discusión en torno a las secciones definidas.

- Fomentar la diversidad institucional y geográfica de los autores que participan en la publicación.

- Potenciar la discusión de experiencias e intercambios científicos entre investigadores y profesionales.

- Contribuir a la visión integral de la arquitectura, por medio de la concurrencia y articulación de las secciones mediante la publicación de artículos de calidad.

- Publicar artículos originales e inéditos que han pasado por revisión de pares, para asegurar que se cumplen las normas éticas, de calidad, validez científica, editorial e investigativa.

- Fomentar la divulgación de las investigaciones y actividades desarrolladas en la Universidad Católica de Colombia.
Palabras clave de la Revista de Arquitectura (Bogotá): arquitectura, diseño, educación arquitectónica, proyecto y construcción, urbanismo.

Idiomas de publicación: español, inglés, portugués y francés. Título abreviado: Rev. Arquit.

\section{Titulo corto: RevArq}

\section{Políticas de sección}

La revista se estructura en tres secciones correspondientes a las líneas de investigación activas y aprobadas por la institución, y dos complementarias, que presentan dinámicas propias de la Facultad de Diseño y las publicaciones relacionadas con la disciplina.

Cultura y espacio urbano. En esta sección se publican los artículos que se refieren a fenómenos sociales en relación con el espacio urbano, atendiendo aspectos de la historia, el patrimonio cultural y físico, y la estructura formal de las ciudades y el territorio.

Proyecto arquitectónico y urbano. En esta sección se presentan artículos sobre el concepto de proyecto, entendido como elemento que define y orienta las condiciones proyectuales que devienen en los hechos arquitectónicos o urbanos, y la forma como estos se convierten en un proceso de investigación y nuevo de conocimiento. También se presentan proyectos que sean resultados de investigación, los cuales se validan por medio de la ejecución y transformación en obra construida del proceso investigativo. También se contempla la publicación de investigaciones relacionadas con la pedagogía y didáctica de la arquitectura, el urbanismo y el diseño.

Tecnología, medioambiente y sostenibilidad. En esta sección se presentan artículos acerca de sistemas estructurales, materiales y procesos constructivos, medioambiente y gestión, relacionados con los entornos social-cultural, ecológico y económico.

Desde la Facultad. En esta sección se publican artículos generados en la Facultad de Diseño, relacionados con las actividades de docencia, extensión, formación en investigación o internacionalización, las cuales son reflejo de la dinámica y de las actividades realizadas por docentes, estudiantes y egresados; esta sección no puede superar el $20 \%$ del contenido.

Textos. En esta sección se publican reseñas, traducciones y memorias de eventos relacionados con las publicaciones en Arquitectura y Urbanismo.

\section{A Frecuencia de publicación}

Desde 1999 y hasta el 2015, la Revista de Arquitectura (Bogotá) publicó un volumen al año, a partir del 2016 se publicarán dos números por año en periodo anticipado, enero-junio y julio-diciembre, pero también maneja la publicación anticipada en línea de los artículos aceptados (versión Post-print del autor).

La Revista de Arquitectura (Bogotá) se divulga mediante versiones digitales (PDF, HTML, EPUB, XML) e impresascon un tiraje de 700 ejemplares, los tiempos de producción de estas versiones dependerán de los cronogramas establecidos por la editorial.

Los tiempos de recepción-revisión-aceptación pueden tardar entre seis y doce meses dependiendo del flujo editorial de cada sección y del proceso de revisión y edición adelantado.

Con el usuario y contraseña asignados, los autores pueden ingresar a la plataforma de gestión editorial y verificar el estado de revisión, edición o publicación del artículo.
A Canje

La Revista de Arquitectura (Bogotá) está interesada en establecer canje con publicaciones académicas, profesionales o científicas del área de Arquitectura y Urbanismo, como medio de reconocimiento y discusión de la producción científica en el campo de acción de la publicación.

\section{Mecanismo}

Para establecer canje por favor descargar, diligenciar y enviar el formato: RevArq FP20 Canjes

\section{Universidad Católica de Colombia (2019, enero-junio). Revista de Arquitectura (Bogotá), $2 I(\mathrm{I})$ I-120. Doi: 10.14718 \\ ISSN: 1657-0308 E-ISSN: 2357-626X \\ Especificaciones: Formato: $34 \times 24 \mathrm{~cm}$ Papel: Mate $115 \mathrm{~g}$ Tintas: Negro y policromía}

A Contacto

Dirección postal:

Avenida Caracas No. 46-72.

Universidad Católica de Colombia

Bogotá D.C.(Colombia)

Código postal: 111311

Facultad de Diseño

Centro de Investigaciones (CIFAR).

Sede El Claustro. Bloque "L", 4 piso

Diag. 46a No. $15 b-10$

Editor, Arq. César Eligio-Triana

Teléfonos:

+57 (1) $3277300-3277333$

Ext. $3109 ; 3112$ o 5146

Fax: +57 (1) 2858895
Correo electrónico:

revistadearquitectura@ucatolica.edu.co

cifar@ucatolica.edu.co

Página WEB:

www.ucatolica edu.co

vínculo Revistas científicas

http://publicaciones.ucatolica.edu.co revistas-cientificas

http://editorial.ucatolica.edu.co/ojsucatolica/revistas_ucatolica/index.php/RevArq 
Universidad Católica de Colombia

Presidente

Édgar Gómez Betancourt

Vicepresidente - Rector

Francisco José Gómez Ortiz

Vicerrector Jurídico

Edwin de Jesús Horta Vásquez

Vicerrector Administrativo

Édgar Gómez Ortiz

Vicerrector Académico

Elvers Medellín Lozano

Vicerrector de Talento Humano

Ricardo López Blum

Director de Investigaciones

Edwin Daniel Durán Gaviria

Directora Editorial

Stella Valbuena García

\section{Facultad de Diseño}

Decano

Werner Gómez Benítez

Director de docencia

Jorge Gutiérrez Martínez

Directora de extensión

Mayerly Rosa Villar Lozano

Director de investigación

Hernando Verdugo Reyes

Director de gestión de calidad

Augusto Forero La Rotta

Comité asesor externo

Facultad de Diseño

Édgar Camacho Camacho

Martha Luz Salcedo Barrera

Samuel Ricardo Vélez
Facultad de Diseño

Centro de Investigaciones - CIFAR

\section{REVISTA DE ARQUITECTURA \\ Revista de Arquitectura \\ (Bogotá)}

Revista de acceso abierto,

arbitrada e indexada

Publindex: Categoría B. Índice Bibliográfico Nacional IBN.

Esci: Emerging Source Citation Index.

Doaj: Directory of Open Access Journals.

Redalyc: Red de Revistas Cientificas de América Latina y el Caribe,

España y Portugal.

SciELO: Scientific Electronic Library Online - Colombia

Redib: Red Iberoamericana de Innovación y Conocimiento Cientifico.

Ebsco: EBSCOhost Research Databases.

Clase: Base de datos bibliográfica de revistas de ciencias sociales y

humanidades.

Latindex: Sistema Regional de Información en Línea para Revistas

Científicas de América Latina, el Caribe, España y Portugal (Directorio

y catálogo).

Dialnet: Fundación Dialnet - Biblioteca de la Universidad de La Rioja.

LatinRev: Red Latinoamericana de Revistas Académicas en Ciencias

Sociales $y$ Humanidades.

Proquest: ProQuest Research Library.

Miar: Matrix for the Analysis of Journals.

Sapiens Research: Ranking de las mejores revistas colombianas según

visibilidad internacional.

Actualidad Iberoamericana: (Índice de Revistas) Centro de Información

Tecnológica (CIT).

Google Scholar

Arla: Asociación de Revistas latinoamericanas de Arquitectura.

\section{Editorial}

Av. Caracas № 46-72, piso 5

Teléfono: 3277300 Ext. 5145

editorial@ucatolica.edu.co

www.ucatolica.edu.co

http://publicaciones.ucatolica.edu.co)

Impresión:

JaVEGRAF

Calle 46A No82-54 Int. 2

Bogotá, D. C., Colombia

http://www.javegraf.com.co/index.php

Enero de 2019
Director

Werner Gómez Benítez

Editor

César Eligio-Triana

Editores de sección

(1) Myriam Stella Díaz-Osorio

(1) Carolina Rodríguez-Ahumada

(4) Anna Maria Cereghino-Fedrigo

\section{Equipo editorial}

Coordinadora editorial

María Paula Godoy Casasbuenas

mpgodoy@ucatolica.edu.co

Diseño y montaje

Juanita Isaza

juanaisaza@gmail.com

Traductoras

Inglés

Erika Tanacs

etanacs25@gmail.com

Portugués

Roanita Dalpiaz

roanitad@gmail.com

Correctora de estilo

María José Díaz Granados M.

mariajose_dgm@yahoo.com.co

Página Web

Centro de investigaciones (CIFAR)

Distribución y canjes

Claudia Álvarez Duquino

calvarez@ucatolica.edu.co
Comité editorial y científico

Cultura y espacio urbano

Carlos Mario Yory, PhD

Universidad Católica de Colombia. Bogotá, Colombia

Sonia Berjman, $\mathrm{PhD}$

ICOMOS-IFLA, Buenos Aires, Argentina

Juan Carlos Pérgolis, MSc Universidad Piloto de Colombia. Bogotá, Colombia

Beatriz García Moreno, PhD

Universidad Nacional de Colombia. Bogotá, Colombia

Proyecto arquitectónico y urbano

Jean-Philippe Garric, PhD, HDR

Université Paris I Panthéon-Sorbonne. Paris, Francia

Debora Domingo Calabuig, PhD

Universidad Politécnica de Valencia, España

Dania González Couret, PhD

Universidad Tecnológica de La Habana, Cuba

Hugo Mondragón López, PhD Pontificia Universidad Católica de Chile. Santiago, Chile

Juan Pablo Duque Cañas, PhD

Universidad Nacional de Colombia. Bogotá, Colombia

Tecnología, medioambiente y sostenibilidad

Mariano Vázquez Espí, PhD

Universidad Politécnica de Madrid, España

Denise Helena Silva Duarte, PhD Universidade de São Paulo (USP), Brasil

Luis Carlos Herrera Sosa, PhD Universidad Autónoma de Ciudad Juárez, México

Claudio Varini, PhD

Universidad Católica de Colombia. Bogotá, Colombia

Luis Gabriel Gómez Azpeitia, PhD Universidad de Colima. Colima, México 


\section{CONTENIDO}
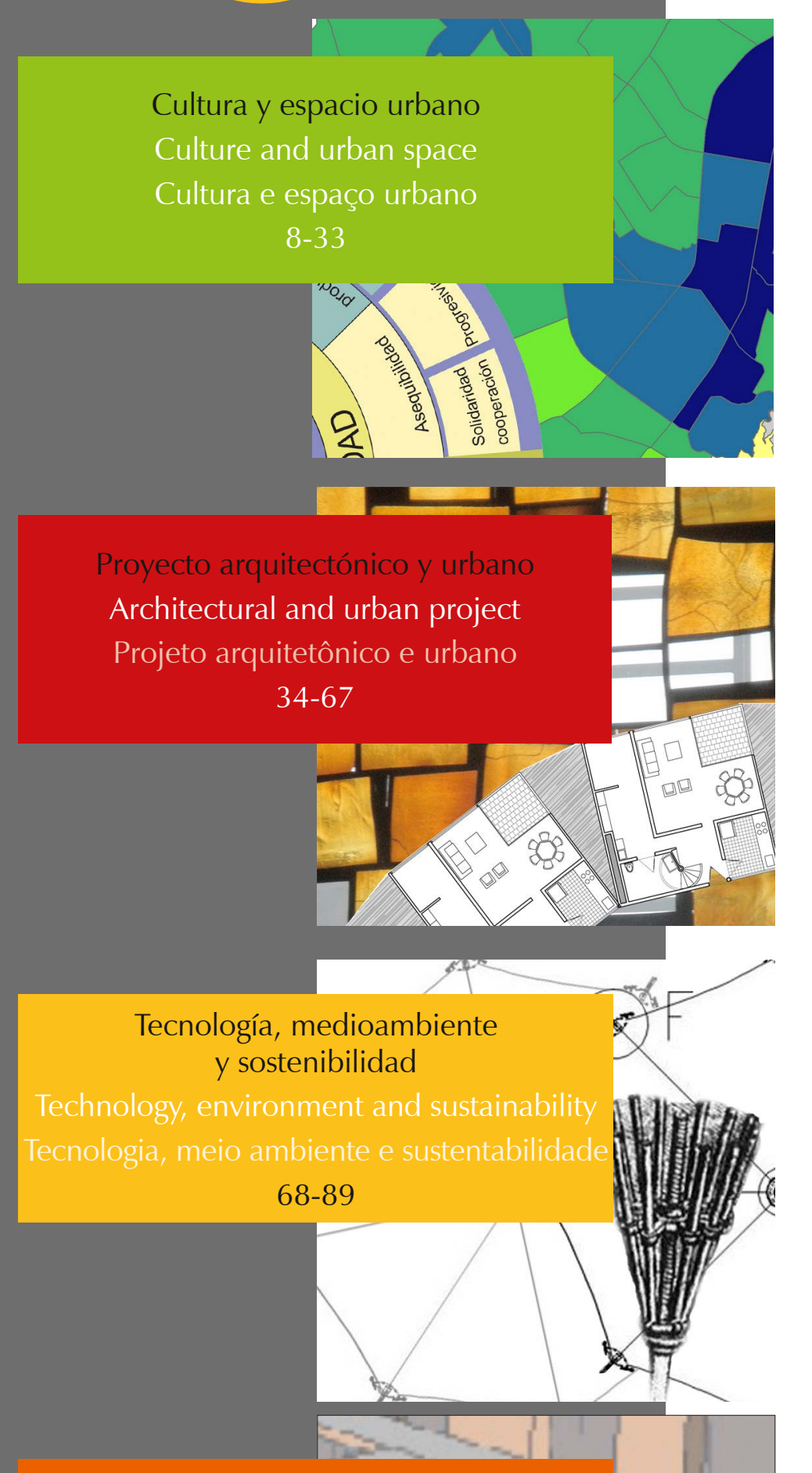

Desde la Facultad

From the Faculty

Da faculdade

90-109

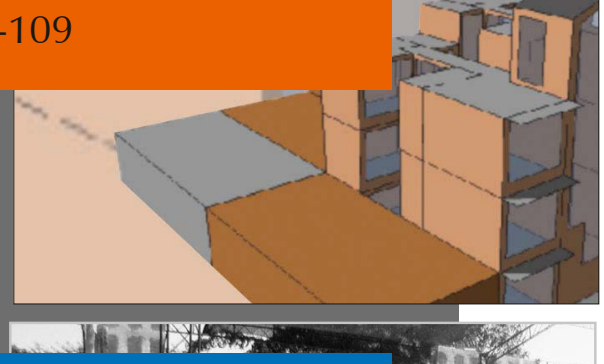

Textos

Texts

Textos

110-118
Revistas en tiempos tecno-humanos

Julio Arroyo

Pág. 3

ES

Índice de caminabilidad para la ciudad de Bogotá

Julián Alberto Gutiérrez-López
Yolanda Beatriz Caballero-Pérez
Rubén Alejandro Escamilla-Triana

ES

Pág. 8

Principios, criterios y propósitos de desarrollo sustentable para la redensificación en contextos urbanos informales
Juan José Castiblanco-Prieto
Fabián Adolfo Aguilera-Martínez
Fabián Alonso Sarmiento-Valdés

Pág. 21

ES

Complejidad y constructivismo en la nueva tradición de la arquitectura de la posguerra

Francisco Javier Fuentes-Farías

Pág. 34 ES

Conservación del arte contemporáneo

El caso de Mathias Goeritz en la Catedral

Metropolitana de México

Alberto Cedeño-Valdiviezo

Pablo Torres-Lima

Pág. 44

\section{ES EN}

Operando desde la forma: un procedimiento

para la valoración de la vivienda colectiva

Julián Camilo Valderrama-Vidal

Pág. 54

ES

Disponibilidad de las técnicas constructivas

de habitación en madera, en Brasil

Victor A. De Araujo

Carlos M. Gutiérrez-Aguilar

Juliana Cortez-Barbosa

Maristela Gava

José N. Garcia

Pág. 68

ES

Diseño y construcción de un paraguas plegable para espacios arquitectónicos

Carlos César Morales-Guzmán

Pág. 76

ES EN

Envolventes eficientes

Relación entre condiciones ambientales, espacios confortables

y simulaciones digitales

Natalia Medina-Patrón

Jonathan Escobar-Saiz

Pág. 90

ES

(Re)pensando el enfoque tecnológico:

el caso del Centro Experimental de la Vivienda

Económica (CEVE) en Argentina

Gustavo Pelegrin

Laila Fleker

Aurelio Ferrero

Pág.110 
La postulación de un artículo a la Revista de Arquitectura (Bogotá) indica que- el o los autores certifican que conocen y aceptan la política editorial, para lo cual firmarán en original y remitirán el formato RevArq FP00 Carta de originalidad.

La Revista de Arquitectura (Bogotá) maneja una política de Autoarchivo VERDE, según las directrices de SHERPA/RoMEO, por lo cual el autor puede:

- Pre-print del autor: Archivar la versión pre-print (la versión previa a la revisión por pares

- Post-print del autor: Archivar la versión post-print (la versión final posterior a la revisión por pares

- Versión de editor/PDF: Archivar la versión del editor - PDF/HTML/XLM en la maqueta de la Revista de Arquitectura (Bogotá).

El Autoarchivo se debe hacer respetando la licencia de acceso abierto, la integridad y la imagen de la Revista de Arquitectura (Bogotá), también se recomienda incluir la referencia, el vínculo electrónico y el DOI.

El autor o los autores son los titulares del Copyright (c) del texto publicado y la Editorial de la Revista de Arquitectura (Bogotá) solicita la firma de una autorización de reproducción del artículo (RevArq FP03 Autorización reproducción), la cual se acoge a la licencia CC, donde se expresa el derecho de primera publicación de la obra.

La Revista de Arquitectura (Bogotá) se guía por las normas internacionales sobre propiedad intelectual y derechos de autor, y de manera particular el artículo 58 de la Constitución Política de Colombia, la Ley 23 de 1982 y el Acuerdo 172 del 30 de septiembre de 2010 (Reglamento de propiedad intelectual de la Universidad Católica de Colombia)

Para efectos de autoría y coautoría de artículos se diferencian dos tipos: "obra en colaboración" y "obra colectiva". La primera es aquella cuya autoría corresponde a todos los participantes al ser fruto de su trabajo conjunto. En este caso, quien actúa como responsable y persona de contacto debe asegurar que quienes firman como autores han revisado y aprobado la versión final, y dan consentimiento para su divulgación. La obra colectiva es aquella en la que, aunque participan diversos colaboradores, hay un autor que toma la iniciativa la coordinación y realización de dicha obra. En estos casos, la autoría corresponderá a dicha persona (salvo pacto en contrario) y será suficiente únicamente con su autorización de divulgación.

El número de autores por artículo debe estar justificado por el tema, la complejidad y la extensión, y no deberá ser superior a la media de la disciplina, por lo cual se recomienda que no sea mayor de cinco. El orden en que se enuncien corresponderá a los aportes de cada uno a la construcción del texto, se debe evitar la autoría ficticia o regalada. Si se incluyen más personas que trabajaron en la investigación se sugiere que sea en calidad de colaboradores o como parte de los agradecimientos. La Revista de Arquitectura (Bogotá) respetará el número y el orden en que figuren en el original remitido. Si los autores consideran necesario, al final del artículo pueden incluir una breve descripción de los aportes individuales de cada uno de firmantes.

La comunicación se establece con uno de los autores, quien a su vez será el responsable de informar a los demás autores de las notificaciones emitidas por la Revista de Arquitectura (Bogotá).

En virtud de mantener el equilibro de las secciones y las mismas oportunidades para todos los participantes, un mismo autor puede postular dos o más artículos de manera simultánea; si la decisión editorial es favorable y los artículos son aceptados, su publicación se realizará en números diferentes.

\section{A Acceso abierto}

La Revista de Arquitectura (Bogotá), en su misión de divulgar la investigación y apoyar el conocimiento y la discusión en los campos de interés, proporciona acceso abierto, inmediato e irrestricto a su contenido de manera gratuita mediante la distribución de ejemplares impresos y digitales. Los interesados pueden leer, descargar, guardar, copiar y distribuir, imprimir, usar, buscar o referenciar el texto completo o parcial de los artículos o la totalidad de la Revista de Arquitectura (Bogotá).

\section{(c) (1) (3)}

Esta revista se acoge a la licencia Creative Commons (CC BY NC de Atribución - No comercial 4.0 Internacional): "Esta licencia permite a otros entremezclar, ajustar y construir a partir de su obra con fines no comerciales, y aunque en sus nuevas creaciones deban reconocerle su autoría y no puedan ser utilizadas de manera comercial, no tienen que estar bajo una licencia con los mismos términos".

La Revista de Arquitectura es divulgada en centros y grupos de investigación, en bibliotecas y universidades, y en las principales facultades de Arquitectura mediante acceso abierto a la versión digital y suscripción anual al ejemplar impreso o por medio de canje, este último se formaliza mediante el formato RevArq FP20 Canjes

Para aumentar su visibilidad y el impacto de los artículos, se envían a bases de datos y sistemas de indexación y resumen (SIR) y, asimismo, pueden ser consultados y descargados en la página web de la revista.

La Revista de Arquitectura no maneja cobros, tarifas o tasas de publicación de artículo (Article Processing Charge-APC), o por el sometimiento de textos a la publicación.

\section{(A) Ética y buenas prácticas}

La Revista de Arquitectura se compromete a cumplir y respetar las normas éticas en todas las etapas del proceso de publicación. Los autores de los artículos publicados darán cumplimiento a los principios éticos contenidos en las diferentes declaraciones y legislaciones sobre propiedad intelectual y derechos de autor específicos del país donde se realizó la investigación. En consecuencia, los autores de los artículos postulados y aceptados para publicar, que presentan resultados de investigación, deben firmar la declaración de originalidad (formato RevArq FP00 Carta de originalidad).

La Revista de Arquitectura reconoce y adopta los principios de transparencia y buenas prácticas descritos por COPE, "Principles of Transparency and Best Practice in Scholarly Publishing" (2015).

El equipo editorial tiene la obligación de guardar la confidencialidad acerca de los artículos recibidos, y abstenerse de usar en sus propias investigaciones datos, argumentos o interpretaciones hasta tanto el artículo no sea publicado. También debe ser imparcial y gestionar los artículos de manera adecuada y en los plazos establecidos. La selección de revisores se hará con objetividad y estos deberán responder a la temática del artículo.

El editor, los autores y los revisores deben seguir las normas éticas internacionales definidas por el Committee on Publication Ethics (COPE), con el fin de evitar casos de:

- Fabricación, falsificación u omisión de datos.

- Plagio y autoplagio.

- Publicación redundante, duplicada o fragmentada.

- Omisión de referencias a las fuentes consultadas.

- Utilización de contenidos sin permiso o sin justificación.

- Apropiación individual de autoría colectiva.

- Cambios de autoría.

- Conflicto de interés (CDI) no revelado o declarado.

- Otras que pudieran surgir en el proceso de investigación y publicación. La fabricación de resultados se genera al mostrar datos inventados por los autores; la falsificación resulta cuando los datos son manipulados y cambiados a capricho de los autores; la omisión se origina cuando los autores ocultan deliberadamente un hecho o dato. El plagio se da cuando un autor presenta como ideas propias datos creados por otros. Los casos de plagio son los siguientes: copia directa de un texto sin entrecomillar o citar la fuente, modificación de algunas palabras del texto, paráfrasis y falta de agradecimientos; el autoplagio se da cuando el mismo autor reutiliza material propio que ya fue publicado, pero sin indicar la referencia al trabajo anterior. La revista se apoya en herramientas digitales que detectan cualquiera de estos casos en los artículos postulados, y es labor de los editores y revisores velar por la originalidad y fidelidad en la citación. La publicación redundante o duplicada se refiere a la copia total, parcial o alterada de un trabajo ya publicado por el mismo autor

En caso de sospechar de alguna mala conducta se recomienda seguir los diagramas de flujo elaborados por COPE (2008), con el fin de determinar las acciones correspondientes.

La Revista de Arquitectura se reserva el derecho de retractación de publicación de aquellos artículos que, posterior a su publicación, se demuestre que presentan errores de buena fe, o cometieron fraudes o malas prácticas científicas. Esta decisión se apoyará en "Retraction Guidelines" (COPE, 2009). Si el error es menor, este se podrá rectificar mediante una nota editorial de corrección o una fe de erratas. Los autores también tienen la posibilidad de solicitar la retractación de publicación cuando descubran que su trabajo presenta errores graves. En todos los casos se conservará la versión electrónica y se harán las advertencias de forma clara e inequívoca.

\section{A Privacidad y manejo de la información.} Habeas Data

Para dar cumplimiento a lo previsto en el artículo 10 del Decreto 1377 de 2013, reglamentario de la Ley 1581 de 2012, y según el Acuerdo 002 del 4 de septiembre de 2013 de la Universidad Católica de Colombia, "por el cual se aprueba el manual de políticas de tratamiento de datos personales":

La Universidad Católica de Colombia, considerada como responsable o encargada del tratamiento de datos personales, manifiesta que los datos personales de los autores, integrantes de los comités y pares revisores, se encuentran incluidos en nuestras bases de datos; por lo anterior, y en cumplimiento de las disposiciones legales vigentes, la Universidad solicitará siempre su autorización, para que en desarrollo de sus funciones propias como Institución de Educación Superior, en especial las relacionadas con la docencia, la extensión y la investigación, la Universidad Católica de Colombia pueda recolectar, recaudar, almacenar, usar, circular, suprimir, procesar, intercambiar, compilar, dar tratamiento, actualizar, transmitir o transferir a terceros países y disponer de los datos que le han suministrado y que han sido incorporados en las bases de datos de todo tipo que reposan en la Universidad.

La Universidad Católica de Colombia queda autorizada, de manera expresa e inequívoca, en los términos señalados por el Decreto 1377 de 2013, para mantener y manejar la información de nuestros colaboradores (autores, integrantes de los diferentes comités y pares revisores); así mismo, los colaboradores podrán ejercer sus derechos a conocer, actualizar, rectificar y suprimir sus datos personales, para lo cual se han dispuesto las siguientes cuentas de correo electrónico: 
La Revista de Arquitectura (Bogotá) recibe artículos de manera permanente. Los artículos se procesan a medida que se postulan, dependiendo el flujo editorial de cada sección.

El idioma principal es el español, y como opcionales están definidos el inglés, el portugués y el francés; los textos pueden ser escritos y presentados en cualquiera de estos.

Los artículos postulados deben corresponder a las categorías universalmente aceptadas como producto de investigación, ser originales e inéditos y sus contenidos responder a criterios de precisión, claridad y brevedad.

Como punto de referencia se pueden tomar las tipologías y definiciones del Îndice Bibliográfico Nacional, Publindex (2010) que se describen la continuación:

1. Artículo de revisión: documento resultado de una investigación terminada donde se analizan, sistematizan e integran los resultados de investigaciones publicadas o no publicadas, sobre un campo en ciencia o tecnología, con el fin de dar cuenta de los avances y las tendencias de desarrollo. Se caracteriza por presentar una cuidadosa revisión bibliográfica de por lo menos 50 referencias.
2. Artículo de investigación científica y tecnológica: documento que presenta, de manera detallada, los resultados originales de proyectos terminados de investigación. La estructura generalmente utilizada contiene cuatro apartes importantes: introducción, metodología, resultados y conclusiones.

3. Artículo de reflexión: documento que presenta resultados de investigación terminada desde una perspectiva analítica, interpretativa o crítica del autor, sobre un tema específico, recurriendo a fuentes originales.

Adicional a estas tipologías, se pueden presentar otro tipo de artículos asociados a procesos de investigación-creación y/o investigación proyectual. En todos los casos se debe presentar la información suficiente para que cualquier investigador pueda reproducir la investigación y confirmar o refutar las interpretaciones defendidas y sea evidente el aporte a la disciplina.

En todos los casos se debe presentar la información suficiente para que cualquier investigador pueda reproducir la investigación y confirmar o refutar las interpretaciones defendidas.

\section{(A) Instrucciones para postular artículos}

Postular el artículo en la página web de la Revista de Arquitectura (Bogotá) y adjuntar comunicación escrita dirigida al editor RevArq_FP00 Carta de originalidad (debidamente firmada por todos los autores en original); de igual manera, se debe diligenciar el formato de hoja de vida RevArq FP01 Hoja de Vida (una por cada autor).

En la comunicación escrita el autor expresa que conoce y acepta la política editorial de la Revista de Arquitectura (Bogotá), que el artículo no está postulado para publicación simultáneamente en otras revistas u órganos editoriales y que no existe conflicto de intereses (ver modelo RevArq FP06 CDI) y que, de ser aceptado, concederá permiso de primera publicación, no exclusiva a nombre de la Universidad Católica de Colombia como editora de la revista.

Los artículos deben tener en cuenta las siguientes recomendaciones:

- En la primera página del documento se debe incluir:

Tírulo: no exceder 15 palabras

Subtítulo: opcional, complementa el título o indica las principales subdivisiones del texto.

Nombre del autor o autores: nombres y apellidos completos o según modelo de citación adoptado por el autor para la normalización de los nombres del investigador. Como nota al pie (máximo 100 palabras) formación académica, experiencia profesional e investigativa, código ORCID https://orcid.org/, e información de contacto, correo electrónico.

Filiación institucional: debajo del nombre se debe declarar la ins-titución en la cual se desarrolló el producto, de la cual recibió apoyo o aquella que respalda el trabajo investigativo.

Resumen: debe ser analítico, se redacta en un solo párrafo, da cuenta del tema, el objetivo, la metodología, los resultados y las conclusiones; no debe exceder las 150 palabras.

Palabras clave: cinco palabras o grupo de palabras, ordenadas alfabéticamente y que no se encuentren en el título o subtítulo; estas sirven para clasificar temáticamente al artículo. Se recomienda emplear principalmente palabras definidas en el tesauro de la Unesco (http://databases. unesco.org/thessp/), en el tesauro de Arte \& Arquitectura (C) (www.aatespanol.cl), o Vitruvio (http://vocabularyserver.com/vitruvio/)

También se recomienda incluir título, resumen y palabras clave en segundo idioma.

- La segunda página y siguientes deben tener en cuenta:

El cuerpo del artículo se divide en: Introducción, Metodología, Resultados y Discusión de resultados; posteriormente se presentan las Conclusiones, y luego las Referencias bibliográficas y los Anexos (modelo IMRYD). Las tablas y figuras se deben incorporar en el texto.

Descripción del proyecto de investigación: en la introducción se debe describir el tipo de artículo y brevemente el marco investigativo del cual es resultado y diligenciar el formato (RevArq FP02 Info Proyectos de Investigación).

TEXTO: todas las páginas deben venir numeradas y con el título de artículo en la parte superior de la página. Márgenes de $3 \mathrm{~cm}$ por todos los lados, interlineado doble, fuente Arial o Times New Roman de 12 puntos, texto justificado (Ver plantilla para presentación de artículos). La extensión de los artículos debe ser de alrededor de 5.000 palabras ( \pm 20 páginas, incluyendo gráficos, tablas, referencias, etc.); como mínimo 3.500 y máximo 8.000 palabras. Se debe seguir el estilo vigente y recomendado en el Manual para Publicación de la American Psychological Association (APA). (Para mayor información véase http://www.apastyle.org/)
Citas y notas al pie: las notas aclaratorias o notas al pie no deben exceder cinco líneas o 40 palabras, de lo contrario estas deben ser incorporadas al texto general. Las citas pueden ser:

Corta: (con menos de 40 palabras) se incorporan al texto y pueden ser: textuales (se encierran entre dobles comillas), parafraseo o resumen (se escriben en palabras del autor dentro del texto).

Cita textual extensa: (mayor de 40 palabras) debe ser dispuesta en un renglón y un bloque independiente con sangrías y omitiendo las comillas, no olvidar en ningún caso la referencia del autor (Apellido, año, página).

Referencias: como modelo para la construcción de referencias se emplea el estilo recomendado en el Manual para Publicación de la American Psychological Association (APA) (http://www.apastyle.org/).

Siglas: en caso de emplear siglas en el texto, las figuras o las tablas, se debe proporcionar la equivalencia completa la primera vez que se empleen y encerrarlas entre paréntesis. En el caso de citar personajes reconocidos se deben colocar nombres o apellidos completos, nunca emplear abreviaturas.

Figuras y tablas: las figuras (gráficos, diagramas, ilustraciones, planos, mapas o fotografías) y las tablas deben ir numeradas y contener título o leyenda explicativa relacionada con el tema del artículo, que no exceda las 15 palabras (Figura 1. xxxxx, Tabla 1. xxxx, etc.) y la procedencia (fuente: autor o fuente, año, página). Estas se deben referenciar en el texto de forma directa o entre paréntesis; se recomienda hacerlo con referencias cruzadas.

También se deben entregar en medio digital, independiente del texto, en formatos editables o abiertos. La marcación de los archivos debe corresponder a la incluida en el texto. Según la extensión del artículo se deben incluir de 5 a 10 gráficos. Ver guía para la búsqueda de imágenes de dominio público o bajo licencias Creative Commons (CC).

El autor es el responsable de adquirir los derechos o las autorizaciones de reproducción a que haya lugar para imágenes o gráficos tomados de otras fuentes, así como de entrevistas o material generado por colaboradores diferentes a los autores; de igual manera, se debe garantizar la protección de datos e identidades para los casos que sea necesario.

FotografíA: pueden ser entregadas en original para ser digitalizadas, de lo contrario se deben digitalizar con una resolución igual o superior a 300 dpi para imágenes a color y 600 para escala de grises. Los formatos de las imágenes pueden ser TIFF, PSD o JPG, y deben cumplir con las características expresadas en el punto anterior (figuras).

Planimetría: se debe entregar la planimetría original en medio digital, en lo posible en formato CAD, y sus respectivos archivos de plumas o en PDF; de no ser posible, se deben hacer impresiones en tamaño carta con las referencias de los espacios mediante numeración y lista adjunta. Deben tener escala gráfica, escala numérica, norte, coordenadas y localización. En lo posible, no deben contener textos, achurados o tramas.

Para más detalles, consultar el documento RevArq Parámetros para Autores Descripción en el portal web de la Revista de Arquitectura (Bogotá)

\section{Beneficios}

Como reconocimiento a los autores, se les hará envío postal de dos ejemplares de la edición impresa sin ningún costo y entregada en la dirección consignada en el formato de hoja de vida (RevArq FP01); adicionalmente, se enviará el vínculo para la descarga de la versión digital.

También se enviará una constancia informativa en la que se relaciona la publicación del artículo y, de manera opcional, se pueden detallar las fechas del proceso editorial y el arbitraje realizado. 
La selección de revisores se realiza de acuerdo con los siguientes criterios:

- Afinidad temática.

- Formación académica.

- Experiencia investigativa y profesional.

- Producción editorial en revistas similares o en libros resultado de investigación.

El proceso de arbitraje se basa en los principios de equidad e imparcialidad, y en los criterios de calidad y pertinencia.

El desarrollo de la revisión se realiza según el formato (RevArq FP10 Evaluación de artículos) y las observaciones que el revisor considere necesarias en el cuerpo del artículo. En cualquiera de los conceptos que emita el revisor (Aceptar, Publicable con modificaciones, Reevaluable o No publicable), y como parte de la labor formativa y de comunidad académica, el revisor hará sugerencias para mejorar et documento. El revisor podrá solicitar una nueva relectura del artículo después de los ajustes realizados por el autor.

El revisor también deberá diligenciar el formato RevArq FP01 Hoja de Vida, con el fin de certificar y soportar el proceso de revisión ante los SIR que así lo soliciten.

En el proceso de arbitraje se emplea el método doble ciego, los nombres del revisor no serán conocidos por el autor y viceversa. Con el fin de garantizar el anonimato del autor, al artículo postulado se le han podido suprimir nombres, instituciones o imágenes que puedan ser asociadas de manera directa al autor.

Aunque se procura el anonimato, una vez recibida la invitación como par revisor del artículo, el revisor debe cerciorarse de que no exista conflicto de intereses (CDI) o alguna limitante que afecte la revisión o que pueda ser vista como tal (lazos familiares, amistad o enemistad, vínculos contractuales o laborales, posiciones éticas, etc.), de presentarse esta situación se notificara al editor. (Ver modelo RevArq FP06 CDI).

Dada la confidencialidad del proceso de revisión, y considerando los derechos de autor y de propiedad intelectual que pueda haber sobre el material que se entrega, el revisor se compromete a mantener en absoluta reserva su labor, a limitar el uso de la obra entregada solo para el propósito designado y a devolver la documentación remitida una vez concluya la actividad.

El tiempo establecido para las revisiones de pares es de máximo un mes a partir de la confirmación de la recepción de la documentación. Ese plazo podrá ser modificado de mutuo acuerdo entre e editor y el revisor, siempre y cuando no afecte la periodicidad de la revista, la impresión o el tiempo para emitir una respuesta al autor.

Los revisores se acogerán a "COPE Ethical Guidelines for Peer Reviewers" de COPE.

\section{Beneficios}

Como retribución a los revisores se les hará envío postal de un ejemplar de la edición impresa sin ningún costo y entregada en la dirección consignada en el formato de hoja de vida. También, si es de interés para el revisor, podrá hacer la solicitud de alguna de las publicaciones editadas y presentes en el catálogo de publicaciones de la UNIVERSIDAD CATÓLICA DE COLOMBIA, previa aprobación de la Editorial y sujeto a la disponibilidad.

Si lo desea tendrá derecho a una constancia de la colaboración en la revisión de artículos, la cual solo contendrá el periodo en el cual se realizó la actividad. También tendrá la posibilidad de aceptar o no la publicación de su nombre, nacionalidad y nivel máximo de formación en la página web de la Revista de Arquitectura (Bogotá) en su calidad de colaborador.

\section{A Proceso de revisión por pares}

Luego de la postulación del artículo, el editor de la Revista de Arquitectura (Bogotá) selecciona y clasifica los artículos que cumplen con los requisitos establecidos en las directrices para los autores. El editor podrá rechazar en primera instancia artículos, sin recurrir a un proceso de revisión, si los considera de baja calidad o por presentar evidencias de faltas éticas o documentación incompleta.

Los artículos se someterán a un primer dictamen del editor, de los editores de sección y del Comité Editorial, teniendo en cuenta:

- Afinidad temática, relevancia del tema y correspondencia con las secciones definidas.

- Respaldo investigativo.

- Coherencia en el desarrollo del artículo, así como una correcta redacción y ortografía.

- Relación entre las figuras y tablas con el texto del artículo.
En esta revisión se verificará el nivel de originalidad mediante el uso de software especializado (Ithenticate o similar) y recursos digitales existentes para tal fin, también se observará la coherencia y claridad en los apartados del documento (modelo IMRYD), la calidad de las fuentes y la adecuada citación, esto quedará consignado en el formato (RevArq FP09 Revisión de artículos); esta información será cargada a la plataforma de gestión editorial y estará a disposición del autor.

En caso de que el artículo requiera ajustes preliminares, será devuelto al autor antes de ser remitido a revisores. En este caso, el autor tendrá veinte días para remitir nuevamente el texto con los ajustes solicitados.

Después de la preselección se asignan mínimo dos revisores especializados, quienes emitirán su concepto utilizando el formato (RevArq FP10 Evaluación de artículos) y las anotaciones que consideren oportunas en el texto; en esta etapa se garantizará la confidencialidad y el anonimato de autores y revisores (modalidad doble ciego).

Del proceso de revisión se emite uno de los siguientes conceptos que será reportado al autor:

\section{- Aceptar el envío: con o sin observaciones.}

- Publicable con modificaciones: se podrá sugerir la forma más adecuada para una nueva presentación, el autor puede o no aceptar las observaciones según sus argumentos. Si las acepta, cuenta con quince días para realizar los ajustes pertinentes.

- Reevaluable: cumple con algunos criterios y debe ser corregido. Es necesario hacer modificaciones puntuales y estructurales al artículo. En este caso, el revisor puede aceptar o rechazar hacer una nueva lectura del artículo luego de ajustado.

- No publicable: el autor puede volver a postular el artículo e iniciar nuevamente el proceso de arbitraje, siempre y cuando se evidencien los ajustes correspondientes.

En el caso de presentarse diferencias sustanciales y contradictorias en los conceptos sobre la recomendación del revisor, el editor remitirá el artículo a un revisor más o a un miembro del Comité Editorial quien podrá actuar como tercer árbitro, con el fin de tomar una decisión editorial sobre la publicación del artículo.

Los autores deberán considerar las observaciones de los revisores o de los editores, y cada corrección incorporada u omitida debe quedar justificada en el texto o en una comunicación adjunta. En el caso que los autores omitan las indicaciones realizadas sin una argumentación adecuada, el artículo será devuelto y no se dará por recibido hasta que no exista claridad al respecto.

El editor respetará la independencia intelectual de los autores y a estos se les brindará el derecho de réplica en caso de que los artículos hayan sido evaluados negativamente y rechazados.

Los autores, con su usuario y contraseña, podrán ingresar a la plataforma de Gestión Editorial, donde encontrarán los conceptos emitidos y la decisición sobre el artículo.

El editor y el Comité Editorial se reservan el derecho de aceptar o no la publicación del material recibido. También se reservan el derecho de sugerir modificaciones de forma, ajustar las palabras clave o el resumen y de realizar la corrección de estilo. El autor conocerá la versión final del texto antes de la publicación oficial del mismo.

Cuando un artículo es aceptado para su publicación, el autor debe firmar la autorización de reproducción (RevArq FP03 Autorización reproducción). Para más información ver: Política de derechos de autor

\section{Notas aclaratorias:}

La Revista de Arquitectura (Bogotá) busca el equilibrio entre las secciones, motivo por el cual, aunque un artículo sea aceptado o continúe en proceso de revisión, podrá quedar aplazado para ser publicado en un próximo número; en este caso, el autor estará en la posibilidad de retirar la postulación del artículo o de incluirlo en el banco de artículos del próximo número.

El editor y los editores de sección de la Revista de Arquitectura (Bogotá) son los encargados de establecer contacto entre los autores y revisores, ya que estos procesos se realizan de manera anónima.
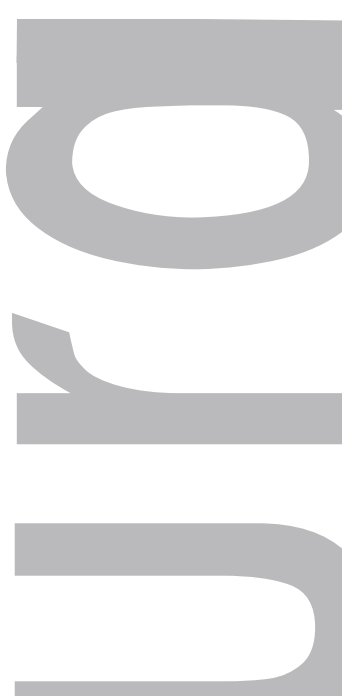
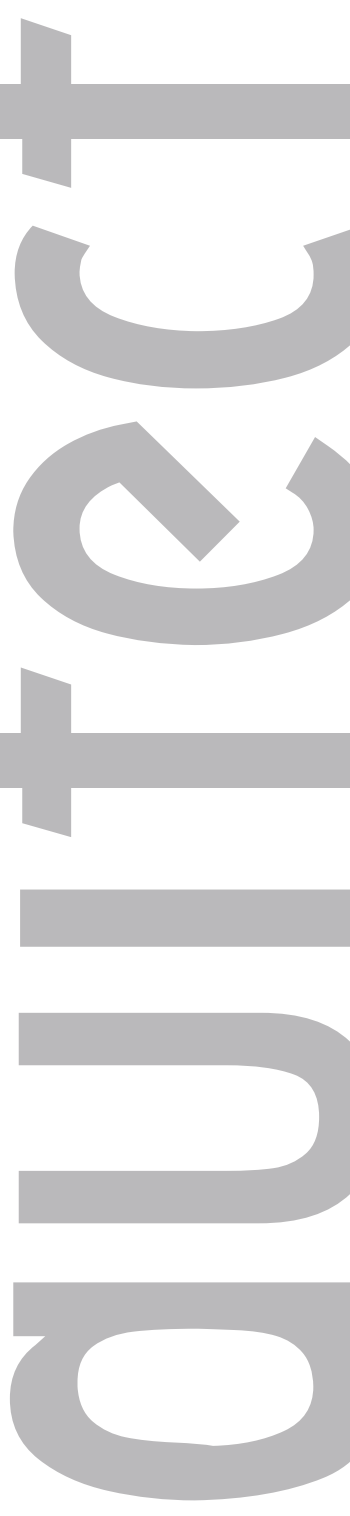

Vol. 


\section{Índice de caminabilidad para la ciudad de Bogotá \\ $\infty \quad$ Walkability index for the city of Bogotá \\ ن Índice de caminhabilidade para a cidade de Bogotá \\ Julián Alberto Gutiérrez-López \\ Yolanda Beatriz Caballero-Pérez
Rubén Alejandro Escamilla-Triana}

Principios, criterios y propósitos de desarrollo sustentable para la $\bar{\Upsilon}$ redensificacion en contextos urbanos informales

Principles, criteria and purposes of sustainable development for

re-densification in unplanned urban context

Princípios, critérios e propósitos de desenvolvimento sustent

Fabián Adolfo Aguilera-Martínez

Fabián Alonso Sarmiento-Valdés

Complejidad y constructivismo en la nueva tradición de la arquitectura de la posguerra

Complexity and constructivism in the new tradition of post-war architecture

U Complexidade e construtivismo na nova tradição da arquitetura do pósguerra

Francisco Javier Fuentes-Farías

Conservación del arte contemporáneo. El caso de Mathias Goeritz en la Catedral Metropolitana de México

Conservation of contemporary art: The case of Mathias Goeritz in the

$\varangle \quad$ Metropolitan Cathedral of Mexico

Conservação da arte contemporânea: o caso de Mathias Goeritz na Catedral Metropolitana do México

\section{Alberto Cedeño-Valdiviezo}

Pablo Torres-Lima

Operando desde la forma: un procedimiento para la valoración de la vivienda colectiva

On Operating based on form: A procedure for the valuation of collective housing

U Operando a partir da forma: um procedimento para avaliar a moradia coletiva

\section{Julián Camilo Valderrama-Vidal}

Disponibilidad de las técnicas constructivas de habitación en

ن Availability of timber housing construction techniques in Brazil

U. Disonibilidade das técnicas construtivas de moradia em madeira no Brasil

\section{Victor A. De Araujo}

Carlos M. Gutiérrez-Aguilar

Juliana Cortez-Barbosa

Maristela Gava

losé N. Garcia

Diseño y construcción de un paraguas plegable

Design and construction of a folding umbrella for architectural spaces

ن Desenho e construção de um guarda-chuva dobrável para espaços arquitetônicos

Carlos César Morales-Guzmán

Envolventes eficientes. Relación entre condiciones ambientales, espacios confortables y simulaciones digitales

(j) Efficient building envelopes: Relationship between environmental conditions,

U. comfortable spaces, and digital simulations

Envolventes eficientes: relação entre condições ambientais, espaços confortáveis e simulações digitais

Natalia Medina-Patrón

Jonathan Escobar-Saiz

(Re)pensando el enfoque tecnológico: el caso del Centro

Experimental de la Vivienda Económica (CEVE) en Argentina

ㅇ $(\mathrm{Re})$ thinking the technological approach: The case of the Experimental Center

으 for Economic Housing (CEVE) in Argentina

ن (Re)pensando a abordagem tecnológica. O caso do Centro Experimental da

Moradia Econômica na Argentina

Gustavo Pelegrin

Laila Fleker

Aurelio Ferrero 